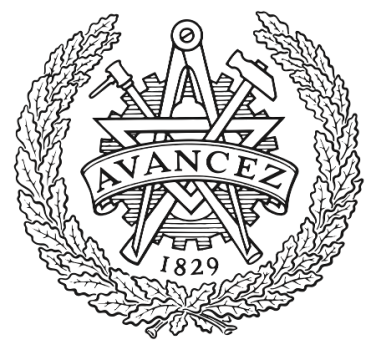

CHALMERS

UNIVERSITY OF TECHNOLOGY

\title{
Alkali Dispersion in (Ag,Cu)(In,Ga)Se2 Thin Film Solar Cells - Insight from Theory and Experiment
}

Downloaded from: https://research.chalmers.se, 2023-04-26 12:07 UTC

Citation for the original published paper (version of record):

Aboulfadl, H., Sopiha, K., Keller, J. et al (2021). Alkali Dispersion in (Ag,Cu)(In,Ga)Se2 Thin Film

Solar Cells - Insight from Theory and

Experiment. ACS Applied Materials \& Interfaces, 13(6): 7188-7199.

http://dx.doi.org/10.1021/acsami.0c20539

N.B. When citing this work, cite the original published paper. 


\title{
Alkali Dispersion in $(\mathrm{Ag}, \mathrm{Cu})(\mathrm{In}, \mathrm{Ga}) \mathrm{Se}_{2}$ Thin Film Solar Cells_-Insight from Theory and Experiment
}

\author{
Hisham Aboulfadl,* Kostiantyn V. Sopiha, Jan Keller, Jes K. Larsen, Jonathan J.S. Scragg, Clas Persson,
} Mattias Thuvander, and Marika Edoff

Cite This: ACS Appl. Mater. Interfaces 2021, 13, 7188-7199

Read Online

\section{ACCESS | 山 W Metrics \& More 四 Article Recommendations | SI Supporting Information}

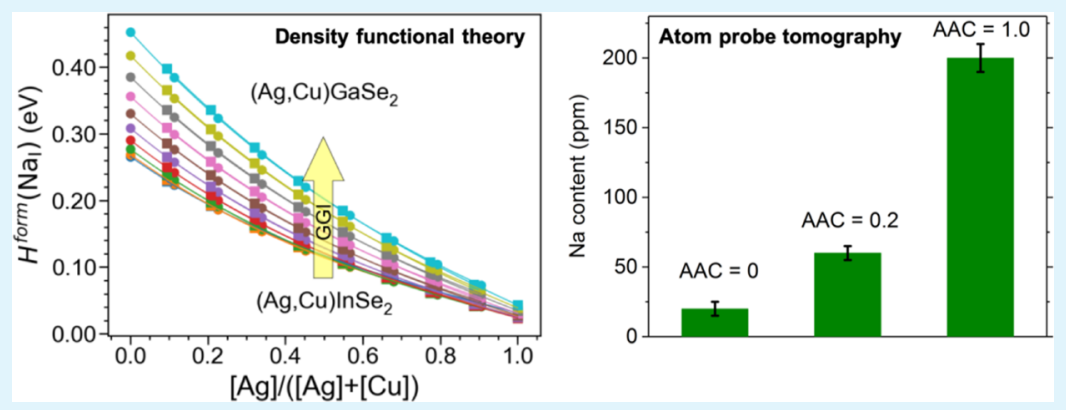

ABSTRACT: Silver alloying of $\mathrm{Cu}(\mathrm{In}, \mathrm{Ga}) \mathrm{Se}_{2}$ absorbers for thin film photovoltaics offers improvements in open-circuit voltage, especially when combined with optimal alkali-treatments and certain Ga concentrations. The relationship between alkali distribution in the absorber and $\mathrm{Ag}$ alloying is investigated here, combining experimental and theoretical studies. Atom probe tomography analysis is implemented to quantify the local composition in grain interiors and at grain boundaries. The Na concentration in the bulk increases up to $\sim 60 \mathrm{ppm}$ for $[\mathrm{Ag}] /([\mathrm{Ag}]+[\mathrm{Cu}])=0.2$ compared to $\sim 20 \mathrm{ppm}$ for films without $\mathrm{Ag}$ and up to $\sim 200 \mathrm{ppm}$ for $[\mathrm{Ag}] /([\mathrm{Ag}]+[\mathrm{Cu}])=1.0$. First-principles calculations were employed to evaluate the formation energies of alkali-on-group-I defects (where group-I refers to $\mathrm{Ag}$ and $\mathrm{Cu})$ in $(\mathrm{Ag}, \mathrm{Cu})(\mathrm{In}, \mathrm{Ga}) \mathrm{Se}_{2}$ as a function of the $\mathrm{Ag}$ and $\mathrm{Ga}$ contents. The computational results demonstrate strong agreement with the nanoscale analysis results, revealing a clear trend of increased alkali bulk solubility with the Ag concentration. The present study, therefore, provides a more nuanced understanding of the role of Ag in the enhanced performance of the respective photovoltaic devices.

KEYWORDS: ACIGS, CIGS, solubility limit, atom probe, density functional theory, first-principles calculations

\section{INTRODUCTION}

$\mathrm{Cu}(\mathrm{In}, \mathrm{Ga}) \mathrm{Se}_{2}$ (CIGSe) photovoltaics is a promising technology combining high power conversion efficiency (PCE), relatively low production cost, excellent outdoor stability, and high radiation hardness. ${ }^{1,2}$ One effective way of enhancing the device performance is by tuning the bandgap energy $\left(E_{\mathrm{g}}\right)$ at different parts of the absorber via adjusting the absorber composition profiles, which in effect also improves band alignment and suppresses recombination at interfaces. CIGSe is thermodynamically stable within a wide range of chemical compositions at usual deposition temperatures, allowing bandgap engineering by alloying, ${ }^{3}$ which motivates the efforts to further boost the PCEs. Tailoring of $E_{\mathrm{g}}$ by alloying can be achieved during processing through varying the composition of the quaternary alloy, typically the $[\mathrm{Ga}] /([\mathrm{Ga}]+[\mathrm{In}])$ ratio (referred to as GGI), incorporation of an additional alloying element (such as $\mathrm{Al}, \mathrm{Ag}, \mathrm{S}$, or $\mathrm{Te}$ ), or combinations thereof. ${ }^{4}$ For CIGSe, the band gap varies from $\sim 1.0 \mathrm{eV}$ for $\mathrm{CuInSe}_{2}$ to $\sim 1.7 \mathrm{eV}$ for $\mathrm{CuGaSe}_{2}$, making the alloy suitable not only for single-junction solar cells but also for tandem applications.
Alloying with Ag to form (Ag,Cu)(In,Ga)Se 2 (ACIGSe) allows lowering the deposition temperature because of a reduction of the melting point, ${ }^{6}$ an improvement of the crystal quality, ${ }^{7,8}$ an increase in the carrier collection length, ${ }^{9}$ and an enhancement of the open-circuit voltage $\left(V_{\mathrm{OC}}\right) \cdot{ }^{10-13} \mathrm{Ag}$ substitutes $\mathrm{Cu}$ in the lattice structure, which decreases the $\mathrm{p}-\mathrm{d}$ hybridization, inducing a downward shift of both band edges and a slight band gap widening. ${ }^{8}$ It has been established that an $[\mathrm{Ag}] /$ $([\mathrm{Ag}]+[\mathrm{Cu}])$ value (referred to as AAC) of approximately 0.2 (at a GGI value of $\sim 0.45$ ) is optimal for improving the PCE of single-junction solar cells. ${ }^{9}$ Hence, ACIGSe is a highly interesting chalcogenide alloy that may eventually outcompete

Received: November 17, 2020

Accepted: January 25, 2021

Published: February 3, 2021 

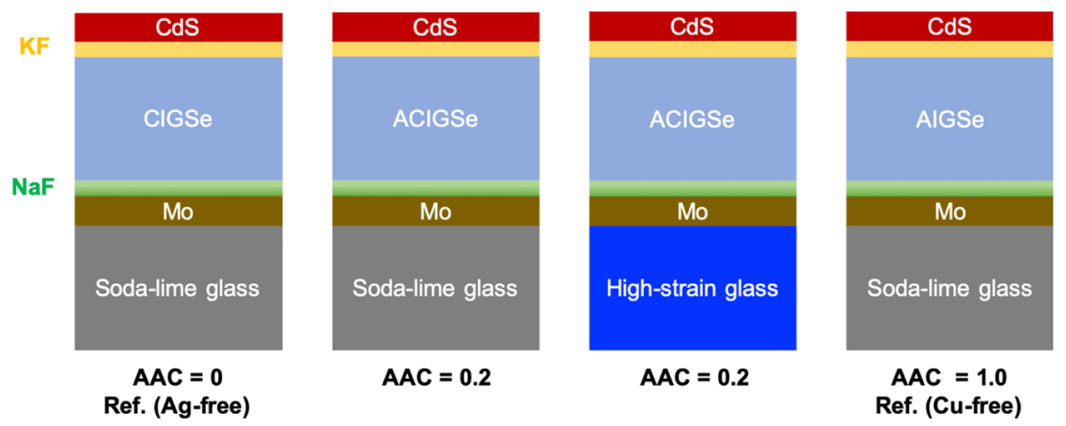

Figure 1. Schematic illustration of the samples studied.

CIGSe if the merits of the $\mathrm{Ag}$ addition for PCE offset the higher cost of raw materials.

Addition of alkali elements into the CIGSe absorber bulk or at its surface is another common practice because of the positive effect on device performance. ${ }^{14,15}$ Increased $V_{\mathrm{OC}}$ and fill factor (FF) are frequently reported for alkali-treated devices, stemming from the increased hole carrier density (improved conductivity) and presumably grain boundary (GB) passivation optimizing local band bending. ${ }^{16,17}$ Alkali elements have limited solubility in CIGSe grain interiors (GIs), ${ }^{18}$ with preferential segregation to lattice defects and phase boundaries in the polycrystalline film. ${ }^{19}$ This is especially apparent for heavy alkali elements (referring to $\mathrm{K}, \mathrm{Rb}$, or $\mathrm{Cs}$ ) because of the higher defect formation energies and increased diffusion barriers in bulk $\mathrm{CIGSe}^{20}{ }^{2}$ Nonetheless, because the volume fraction of GBs is small compared with that of the GIs, the integral $\mathrm{Na}$ amounts can be comparable. ${ }^{21}$ An ambiguity with bulk incorporation, however, is that the most stable alkali-on$\mathrm{Cu}$ defects $\left(\mathrm{Alk}_{\mathrm{Cu}}\right)$ are charge neutral, and thus electrically inactive. ${ }^{20}$ In an attempt to reconcile these results with the observed changes in the hole concentration, ${ }^{22}$ a kinetic model of alkali out-diffusion from GIs to GBs upon cooling was developed. ${ }^{23}$ The situation became even more complicated when a combination of $\mathrm{Na}$ with heavy alkali treatments demonstrated even higher PCEs in CIGSe compared to singlealkali postdeposition treatment (PDT). ${ }^{24}$ Studies on the diffusion mechanism of alkali elements in CIGSe have shown that an interplay occurs between light (referring to $\mathrm{Li}$ and $\mathrm{Na}$ ) and heavy alkalis regarding their distribution in the GIs and at GBs, which is influenced by the substrate temperature as well as the alkali supply dose. ${ }^{22}$ There is still an ongoing debate whether the positive effects of alkali incorporation are related to their dispersion in the GIs or GBs, as well as their modification of the absorber surface. ${ }^{23,25}$ Furthermore, it is reasonable to suppose that the incorporation and influences of alkali elements could vary when the CIGSe absorber is modified by Ag alloying, as described above.

Alkali elements can be introduced via predeposition treatment (alkali-containing precursor layer), coevaporation, or PDT, where the light and/or heavy alkali elements can be chosen. ${ }^{4}$ For heavy alkali elements, PDT is the most common supply technique, whereas light alkali elements can be supplied with all three techniques. Substantial incorporation of alkali elements is also caused by in-diffusion from glass substrates during processing if no diffusion barrier is used. Irrespective of the selected alkali element or doping technique, it has been shown that there is an optimum alkali amount, which if exceeded leads to degradation of $V_{\mathrm{OC}}$ and lower PCE values, observed in both CIGSe and ACIGSe. ${ }^{26-29}$ The effect seems to be more severe in the case of ACIGSe, where the PCE can drop significantly. ${ }^{30}$ It has also been reported for Ag-alloyed $\mathrm{CuInSe}_{2}$ (ACISe). ${ }^{31}$ This could be anticipated because the optimum amount of KF PDT for ACIGSe was found to be lower compared to CIGSe synthesized under similar conditions. ${ }^{1,26}$ Understanding the underlying cause of this distinction is critical to further development of successful PDT strategies. Although the reason for this variance is currently unknown, it could be because of the differences in (1) solubility limits for alkalis (i.e., a thermodynamic effect) or (2) rate of in-diffusion from the alkali-rich source (i.e., a kinetic effect). There are some studies supporting both hypotheses. Kim et al. ${ }^{11}$ showed using secondary ion mass spectrometry (SIMS) that the $\mathrm{Na}$ concentration in the absorber increases upon addition of $\mathrm{Ag}$ in CIGSe grown on soda-lime glass (SLG) substrates, with the authors arguing in favor of faster indiffusion of alkalis in ACIGSe. However, in a more recent study of ACIGSe/CIGSe tandem devices, ${ }^{12}$ the same authors presented SIMS profiles with nearly an order of magnitude stronger $\mathrm{Na}$ signal within the ACIGSe top layer compared to the CIGSe bottom cell. Considering that the only source of alkalis was the SLG substrate, all $\mathrm{Na}$ in the top cells must have diffused through the bottom CIGSe cell first. As such, the preference for $\mathrm{Na}$ accumulation in the top ACIGSe cell points to higher alkali solubility in ACIGSe.

It, therefore, remains unclear how alkali elements are distributed in ACIGSe and what role they play in enhancing the performance of CIGSe devices upon Ag alloying. Among the few experimental techniques capable of investigating local compositions of GBs and GIs, atom probe tomography (APT) has been proven exceptionally useful for quantitative elemental mapping in three dimensions. ${ }^{19,21,32-45}$ To utilize this unique capability, we perform in this work a comparative APT characterization of alkali distributions in polycrystalline ACIGSe and CIGSe films. Additionally, we employ firstprinciples calculations within the density functional theory (DFT) to verify and explain the experimental trends in solubility. With the synergy of these methods, we can draw a clearer picture of the complex phenomena behind the improved efficiency of ACIGSe and CIGSe absorbers with alkali incorporation.

\section{EXPERIMENTAL AND COMPUTATIONAL METHODS}

2.1. Solar Cell Processing. Two different glass substrates were used, namely SLG, which is Na-rich and high-strain glass (HSG), which is K-rich. Mo back contacts were DC-sputtered (target purity $99.97 \%$ ) on the cleaned glass substrates, followed by evaporation of $\sim 15 \mathrm{~nm}$ thick NaF alkali precursor layers. CIGSe, ACIGSe, and $\mathrm{Ag}(\mathrm{In}, \mathrm{Ga}) \mathrm{Se}_{2}$ (AIGSe) absorbers were coevaporated in a three-stage 
process using metal targets (99.999\% purity) and $4 \mathrm{~N}$ Se target ( $99.99 \%$ purity). The three-stage process follows an evaporation profile consisting of I-poor, I-rich, and finally I-poor stages, with all stages having the same $[\mathrm{Ag}] /[\mathrm{Cu}]$ ratio for ACIGSe. The CIGSe $(\mathrm{Ag}$ free, $\mathrm{AAC}=0)$ and AIGSe $(\mathrm{Cu}$-free, $\mathrm{AAC}=1)$ devices grown on SLG were produced here to be used for comparison (reference samples). The substrate temperature was about $400{ }^{\circ} \mathrm{C}$ in the first stage and ramped up to about $550{ }^{\circ} \mathrm{C}$ in the following two stages. The deposition time for the absorber layers was about $30 \mathrm{~min}$, resulting in film thicknesses of around $2 \mu \mathrm{m}$. High-Ga and low-In deposition rates were used at the initial stage of the absorber deposition to induce a Ga grading at the back contact. The elemental AAC, GGI, and $([\mathrm{Ag}]+$ $[\mathrm{Cu}]) /([\mathrm{Ga}]+[\mathrm{In}])([\mathrm{I}] /[\mathrm{III}])$ ratios in the absorbers were determined using X-ray fluorescence (XRF) spectroscopy. KF PDT was performed on all samples for $10 \mathrm{~min}$ after ramping down the substrate temperature to $350{ }^{\circ} \mathrm{C}$ at a rate of approximately $5{ }^{\circ} \mathrm{C} / \mathrm{min}$. A $40 \mathrm{~nm}$ CdS buffer layer was deposited using chemical bath deposition (CBD). A $125 \mathrm{ml}$ solution with $4.5 \mathrm{mM}$ Cd acetate and 1.7 $\mathrm{M}$ ammonium hydroxide was preheated in a $60{ }^{\circ} \mathrm{C}$ water bath, after which $50 \mathrm{~mL}$ of thiourea $(0.35 \mathrm{M})$ was added and the samples were immersed. The CdS growth was terminated after $6 \mathrm{~min}$, after which the samples were rinsed and dried. Schematic of the four samples investigated is shown in Figure 1. Devices used for electronic measurements were completed by depositing a front stack of $100 \mathrm{~nm}$ of undoped $\mathrm{ZnO}$, followed by $200 \mathrm{~nm}$ of $\mathrm{ZnO} / \mathrm{Al}$ using $\mathrm{RF}$ magnetron sputtering (both targets of $99.99 \%$ purity). A metal stack of $\mathrm{Ni}-\mathrm{Al}-\mathrm{Ni}$ was deposited by electron beam evaporation through a shadow mask (target purity: $99.9 \% \mathrm{Ni}$ and $99.999 \% \mathrm{Al}$ ). Finally, cells with an area of $0.5 \mathrm{~cm}^{2}$ were defined by mechanical scribing. $J V$ data are extracted from standard test conditions. All measurements were done sweeping from low to high voltage, with no significant hysteresis effects observed. The temperature during measurements was controlled to $25{ }^{\circ} \mathrm{C}$ by a metal plate cooled with a Peltier element (no preconditioning used). Illumination was made using a halogen light calibrated to a photon flux corresponding to $1000 \mathrm{~W} / \mathrm{m}^{2}$ with a calibration $\mathrm{Si}$ solar cell. External quantum efficiency (EQE) measurements were carried out and the EQE intensity was used to calculate the current density under short circuit conditions using the data for AM1.5 spectral distribution.

2.2. Materials Characterization. Glow discharge optical emission spectroscopy (GDOES) elemental profile measurements were performed on the devices in a Spectruma Analytik GDA $750 \mathrm{HR}$ system. A dual-beam focused ion-beam/scanning electron microscope (FIB/SEM) instrument (Thermo-Fisher Versa 3D) was used to carry out site-specific specimen preparations for APT analysis via a standard lift-out technique. ${ }^{46}$ Absorbers without front contacts (incomplete devices) were used for GDOES and APT characterization. A $100 \mathrm{~nm}$ thick Pt layer was deposited on top of the CdS layer using the electron beam in the FIB/SEM to minimize Ga-implantation. An acceleration voltage of $2 \mathrm{kV}$ was used in the final steps of tip shaping to reduce Gaimplantation and surface amorphization effects. Laser-pulsed APT measurements were carried out using a LEAP 3000X HR CAMECA system using a green laser $(\lambda=532 \mathrm{~nm})$ with a laser power set to 0.05 $\mathrm{nJ}$, a repetition rate of $100 \mathrm{kHz}$, and base temperature of $\sim 50 \mathrm{~K}$. 3D reconstructions and data analysis were performed using CAMECA IVAS 3.6.14 software.

2.3. Computational Details. The first-principles calculations were carried out within DFT using the Vienna Ab initio Simulation Package (VASP) ${ }^{47-49}$ The projector augmented wave pseudopotentials ${ }^{50,51}$ with valence electron configurations of $4 \mathrm{~d}^{10} 5 \mathrm{~s}^{1}$ for $\mathrm{Ag}$ $3 \mathrm{~d}^{10} 4 \mathrm{~s}^{1}$ for $\mathrm{Cu}, 4 \mathrm{~d}^{10} 5 \mathrm{~s}^{2} 5 \mathrm{p}^{1}$ for In, $3 \mathrm{~d}^{10} 4 \mathrm{~s}^{2} 4 \mathrm{p}^{1}$ for Ga, $4 \mathrm{~s}^{2} 4 \mathrm{p}^{4}$ for $\mathrm{Se}, 3 \mathrm{~s}^{1}$ for $\mathrm{Na}, 3 \mathrm{p}^{6} 4 \mathrm{~s}^{1}$ for $\mathrm{K}, 4 \mathrm{p}^{6} 5 s^{1}$ for $\mathrm{Rb}$, and $5 s^{2} 5 \mathrm{p}^{6} 6 s^{1}$ for Cs were employed. The calculations were performed with the PerdewBurke-Ernzerhof (PBE) exchange-correlation functional. ${ }^{52}$ All ACIGSe supercells contained 216 atoms with random occupation of the cationic sites (placing $\mathrm{Ag} / \mathrm{Cu}$ on group-I and In/Ga on group-III positions) and were generated using the special quasirandom structure (SQS) algorithm, ${ }^{53}$ as implemented in the Alloy-Theoretic Automated Toolkit (ATAT) package. ${ }^{54}$ The Brillouin-zone integrations were performed using a $2 \times 2 \times 2 \Gamma$-centered Monkhorst-Pack grid $^{55}$ and a cut-off energy of $350 \mathrm{eV}$. The ionic and lattice relaxations were continued until reaching a threshold of $0.01 \mathrm{eV} / \AA$ on atomic forces. For the defect calculations, $\mathrm{NaInSe}_{2}$ was simulated with the delafossite $\left(R \overline{3} m\right.$ [\#166]) structure, whereas $\mathrm{KInSe}_{2}, \mathrm{RbInSe}_{2}$, and $\mathrm{CsInSe}_{2}$ were modeled with a monoclinic $(\mathrm{C} 2 / \mathrm{c}[\# 15])$ cell. In contrast, the supercells of alkali alloys were initialized with a chalcopyrite structure but allowed to change symmetry during relaxation. The analysis was automatized using the Pymatgen library. ${ }^{56}$

\section{RESULTS AND DISCUSSION}

\subsection{Absorber Composition and Device Performance.} The absorber compositions were initially determined by XRF. The elemental AAC, GGI, and [I]/[III] of each sample are presented in Table 1 . Device characteristics of the respective

Table 1. Integral Absorber Compositions Measured with XRF

\begin{tabular}{lllc}
\multicolumn{1}{c}{ sample } & AAC & GGI & {$[\mathrm{I}] /[\mathrm{III}]$} \\
CIGSe-SLG & 0 & 0.38 & 0.89 \\
ACIGSe-SLG & 0.22 & 0.40 & 0.89 \\
ACIGSe-HSG & 0.19 & 0.43 & 0.87 \\
AIGS-SLG & 1 & 0.40 & 0.85 \\
\hline
\end{tabular}

samples are presented in Table 2. For ACIGSe, the absorber deposited on HSG showed slightly higher $J_{S C}$ and PCE values compared to the films grown on SLG.

3.2. Alkali Distribution Profiles along the ACIGSe Absorber Thickness. Figure 2 shows GDOES profiles of alkalis in ACIGSe absorbers grown on the different substrates. The profiles start at the CdS/ACIGSe interface and end in the Mo layer. The absorber film grown on HSG was slightly thinner compared to the one grown on SLG, with the measured thicknesses of $\sim 1.7$ and $\sim 2.1 \mu \mathrm{m}$, respectively (determined by XRF and verified with cross-sectional SEM images). Both films displayed an increase in $\mathrm{Na}$ and $\mathrm{K}$ concentrations at the CdS/ACIGSe and ACIGSe/Mo interfaces. As expected, the $\mathrm{K}$ increase at the back contact is more pronounced for the HSG substrate. Similar alkali profiles were reported in our previous work for CIGSe and ACIGSe, ${ }^{10,57}$ as well as in multiple other studies reviewed in ref 22 .

The main optoelectronic effects of alkali segregation at the interfaces are suggested to be similar to those of alkalis dispersed in GBs, such as defect passivation and local band bending. ${ }^{58}$ However, in addition, alkali enrichment at the heterojunction can promote alkali-rich compound formation (such as AlkInSe ${ }_{2}$ ), ${ }^{59}$ interactions with ordered defect compound (ODC) phases, ${ }^{44,57}$ as well as altering the growth behavior of the buffer layer. ${ }^{58,60}$ Surface chemical analysis was performed here using energy-dispersive X-ray spectroscopy (EDS) in SEM and revealed no alkali-rich compounds, despite the clear alkali enrichment identified at the absorber surface using GDOES. Thus, the quantities of these compounds were below the sensitivity limit of EDS or they were not stable under the electron beam. In our previous study on alkali treatment of $\mathrm{ACIGSe}{ }^{26}$ we demonstrated that the alkali-rich surface compound, (Ag, $\mathrm{K}) \mathrm{InSe}_{2}$, only begins to form in samples treated with an excessive dose of KF. It is necessary to mention, however, that GDOES provides only qualitative analysis of the alkali distribution. Furthermore, it delivers indepth compositional information averaged over a spot with a diameter of $\sim 2 \mathrm{~mm}$. Hence, interpretation of the GDOES 
Table 2. Solar Cell Parameters for Selected Devices with the Standard Grid and without Antireflective Coating ${ }^{a}$

\begin{tabular}{ccccc} 
sample & $V_{\mathrm{OC}}[\mathrm{mV}]$ & $J_{\mathrm{SC}}\left[\mathrm{mA} / \mathrm{cm}^{2}\right]$ & FF $[\%]$ & PCE $[\%]$ \\
CIGSe-SLG & $704(706 \pm 3)$ & $31.8(30.7 \pm 0.3)$ & $75.3(75.0 \pm 1.2)$ & $16.8(16.3 \pm 0.4)$ \\
ACIGSe-SLG & $769(761 \pm 6)$ & $30.2(30.1 \pm 0.2)$ & $77.9(74.8 \pm 2.6)$ & $18.1(17.4 \pm 0.7)$ \\
ACIGSe-HSG & $770(759 \pm 10)$ & $31.0(30.7 \pm 0.2)$ & $77.7(76.8 \pm 0.6)$ & $18.6(17.9 \pm 0.5)$ \\
AIGSe-SLG & $682(667 \pm 5)$ & $25.1(24.4 \pm 0.9)$ & $68.2(66.4 \pm 1.7)$ & $11.6(10.7 \pm 0.4)$ \\
\multicolumn{2}{l}{ a Average values with their standard deviations are given in parentheses. } & &
\end{tabular}
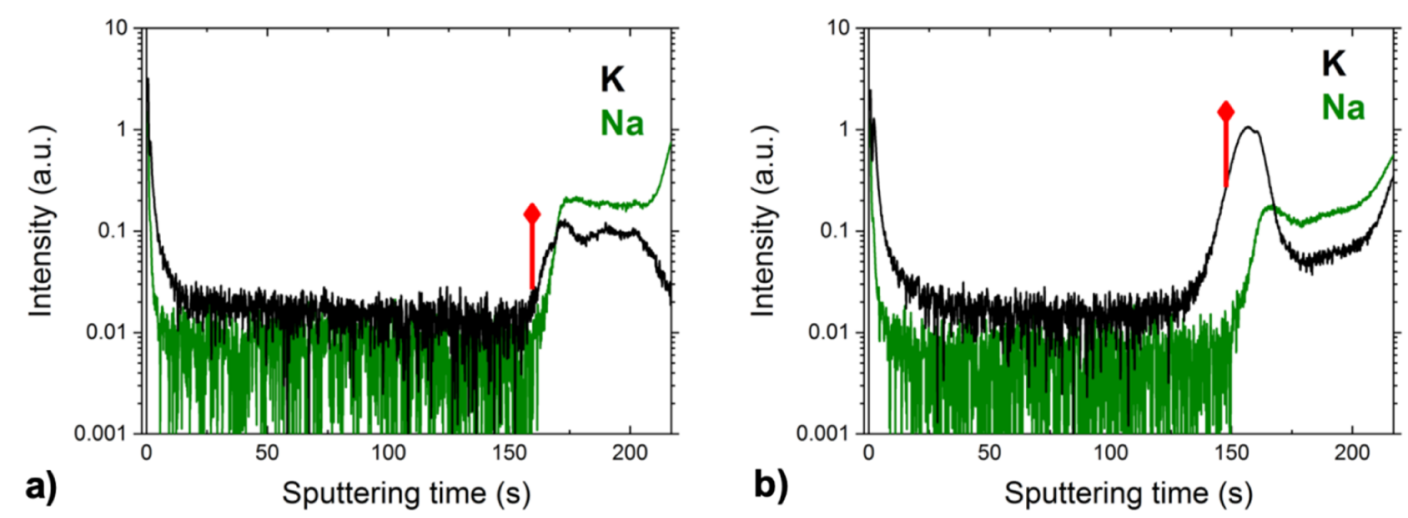

Figure 2. GDOES depth profiles for ACIGSe samples on (a) SLG and (b) HSG, showing K and Na signals from the CdS/ACIGSe interface to the Mo back contact. The onset of the Mo signal is marked in red color.

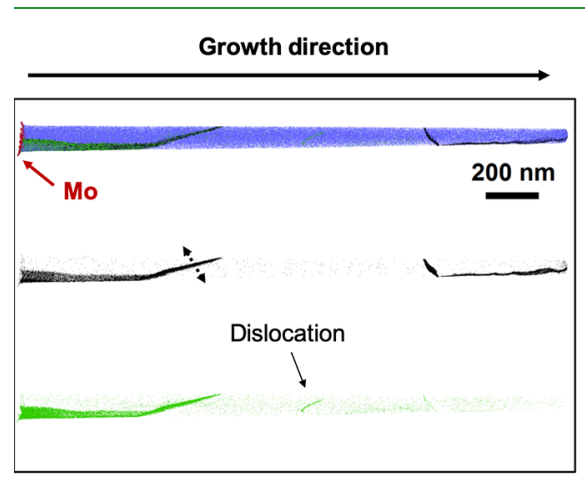

GB

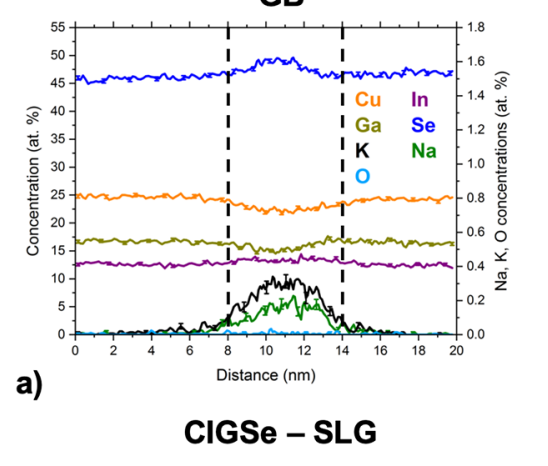

Figure 3. APT analysis of GBs in the CIGSe (SLG) and both ACIGSe samples. 1D concentration profiles are shown below the respective reconstructions. The uppermost reconstructions show overlaid Se (blue), K (black), and Na (green) atoms, with individual reconstructions for alkalis shown separately below. (a) CIGSe grown on SLG (reference) showing four GBs in the absorber and a Na-decorated dislocation. Some GBs appear thicker because the GB planes are not parallel to the viewing direction. The $1 \mathrm{D}$ profile is measured across the GB highlighted by dotted arrows. (b) ACIGSe grown on SLG and (c) ACIGSe grown on HSG, both showing one GB per reconstruction.

scans should be made with caution. Local compositional analysis was performed here on the CdS/ACIGSe interface using APT, where alkali segregation was found to be inhomogeneous at the nanometer scale (see Figure S1 in Supporting Information), that is, partial segregation occurs across the entire interface. This indicates that at a fine scale, the alkali is most likely to be distributed as islands at the CdS/
ACIGSe interface. The alkali concentrations at the interface are well below 1 at. \%, which is unfortunately not possible to map using SEM-EDS, for instance.

It seems likely that the alkali segregation detected using GDOES near the surface is not connected with nucleation of ODCs because no clear group-I depletion is observed (not presented here). The formation of ODCs is governed by the 
CIGSe - SLG

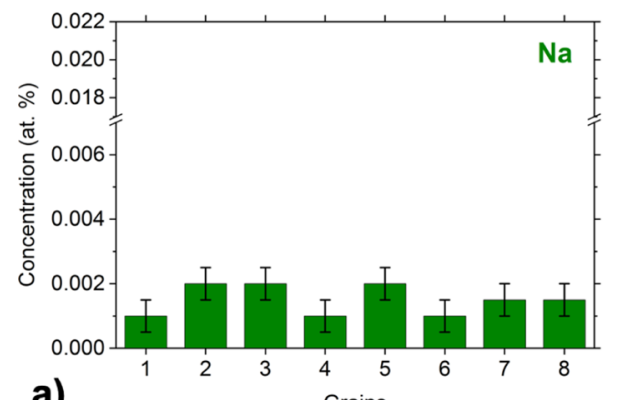

a)

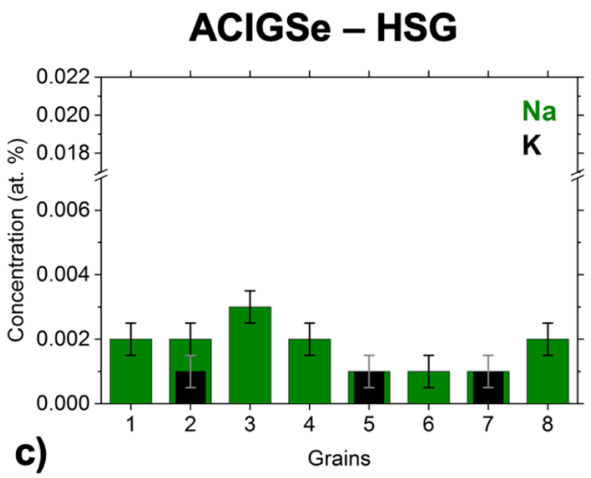

ACIGSe - SLG

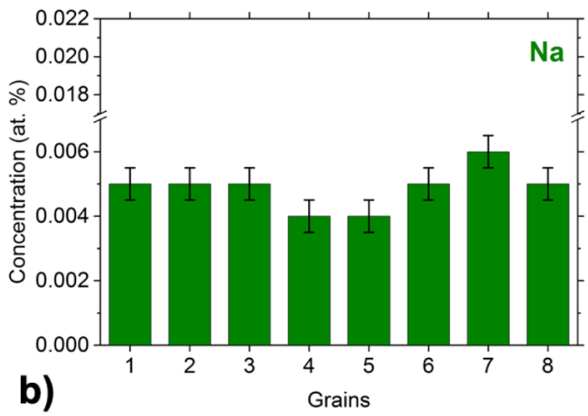

AIGSe - SLG

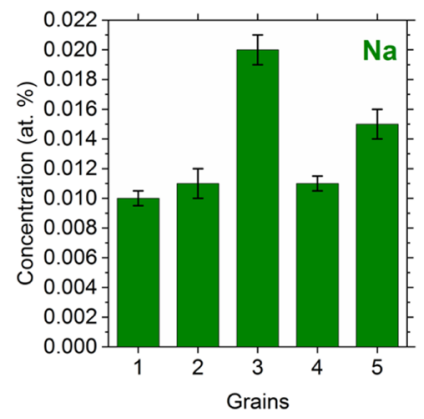

Figure 4. Alkali concentrations measured with APT in different grains of (a) CIGSe grown on SLG, (b) ACIGSe grown on SLG, (c) ACIGSe grown on HSG, and (d) AIGSe grown on SLG.

absorber composition, specifically the $[\mathrm{I}] /[\mathrm{III}]$ ratio, as we have recently shown for wide-gap ACIGSe. ${ }^{57}$

3.3. Nanoscale Analysis of Alkali Dispersion by Atom Probe Tomography. In addition to GDOES depth profiling, spatial distributions of the matrix and alkali elements in three dimensions were examined at the nanoscale using APT. The primary objective is analyzing the composition at GBs and in GIs, separately. Because of the limited volume analyzed using this technique and the compositional variations between grains, a minimum of five successful APT measurements was carried out from each sample with datasets of at least 10 million atoms, in order to attain reasonable statistics.

3.3.1. Grain Boundaries. The effect of Ag alloying on the GB composition and alkali dispersion is investigated here by analyzing the two ACIGSe samples and comparing them to the CIGSe absorber grown on SLG (Ag-free reference sample). Figure 3 shows APT analyses of the three samples. Each presented 3D reconstruction includes at least one GB. In all cases, the concentrations of matrix elements in the GBs differ from those in the adjacent grains, which is a common observation in CIGSe. ${ }^{32-35,38-40,42,45}$ The GBs here display slight $\mathrm{Cu}$-depletion and In-enrichment, which is especially evident for the ACIGSe samples. Interestingly, the measured Ag profiles are almost flat, translating into an increasing AAC ratio in the GBs. According to two earlier extensive APT studies, ${ }^{42,61}$ it is now understood that the majority of GBs in CIGSe exhibit this kind of $\mathrm{Cu}$-depletion. This tendency has also been reported using high-resolution XRF for CIGSe after RbF PDT. ${ }^{62}$ The compositional fluctuations of matrix elements at GBs are claimed to influence the electrical characteristics of solar cells because of the local band bending, ${ }^{63}$ which can have beneficial, detrimental, or neutral impact on the device performance. ${ }^{32}$ For instance, $\mathrm{Cu}$-depleted GBs are argued to reduce carrier recombination because they act as hole barriers because of a downshift of the valence band maximum. ${ }^{64}$ Although structural information on planar defects is usually not accessible by APT, the observed features resemble random high-angle GBs and not stacking faults or twin boundaries. Such a distinction can be made from an irregular curvature of interfaces, which stems from an arbitrary connectivity of faceted grains in the absorber.

Segregation of alkali elements at the GBs is observed for all samples. Both $\mathrm{Na}$ and $\mathrm{K}$ are found in dissimilar quantities at different GBs, which agrees with previous studies on CIGSe. $^{40,42,61}$ The effective thickness of the GBs, measured by the compositional change at the interfaces, was in the range of 4-6 nm (see Figure 3). The extent of alkali segregation can be additionally quantified by calculating the Gibbs interfacial excess $(\Gamma)$ values. $^{65}$ The values were extracted for all GBs shown in Figure 3. In the CIGSe sample, the $\Gamma_{\mathrm{Na}}$ and $\Gamma_{\mathrm{K}}$ values varied among the four GBs recognized in Figure 3a from 0.03 to 2.74 at. $/ \mathrm{nm}^{2}$ and from 0.97 to 3.14 at. $/ \mathrm{nm}^{2}$, respectively. In the ACIGSe sample grown on SLG, the $\Gamma_{\mathrm{Na}}$ and $\Gamma_{\mathrm{K}}$ values in the single GB seen in Figure $3 \mathrm{~b}$ were 0.83 and 1.87 at. $/ \mathrm{nm}^{2}$, respectively. For comparison, in the ACIGSe sample grown on HSG, the $\Gamma_{\mathrm{Na}}$ and $\Gamma_{\mathrm{K}}$ values in the GB shown in Figure $3 \mathrm{c}$ were 0.04 and 3.66 at. $/ \mathrm{nm}^{2}$, respectively. Traces of $\mathrm{O}$ were detected at some GBs for each of the samples investigated, which is a common finding in CIGSe and CZTS absorbers. ${ }^{66,67}$ Oxygen contamination is argued to arise primarily through diffusion from the substrate and/or surface oxidation before deposition of a buffer layer. Preferential $O$ segregation is reported for GBs with a specific misorientation angle, ${ }^{40}$ but no such correlation has been established for alkali elements. ${ }^{61}$ Herein, we observe no significant difference in the behavior of alkalis at GBs of ACIGSe and CIGSe. However, three important observations can be made: (1) concentrations of alkalis are dissimilar in different GBs within the same sample, 
which is in agreement with earlier APT studies on CIGSe. $^{40,42,61}$ (2) $\mathrm{K}$ segregation is more consistently observed compared to $\mathrm{Na}$, with some GBs being nearly devoid of $\mathrm{Na}$, even in the absorber grown on SLG, as seen in Figure 3a. (3) GBs in the ACIGSe sample grown on the HSG substrate show greater $\mathrm{K}$ segregation and only small traces of $\mathrm{Na}$. Hence, this indicates that the HSG substrate is clearly the leading source of $\mathrm{K}$ in the GBs. According to the model/hypothesis of interplay between light and heavy alkali elements in GBs and GIs of chalcopyrite thin films (ion exchange mechanism), ${ }^{22,68}$ it is understood that heavier alkalis replace $\mathrm{Na}$ at the GBs if supplied in a higher dosage or if the films are deposited at higher temperatures. This mechanism is expected to be driven by thermodynamic as well as kinetic factors. An increased concentration of $\mathrm{K}$ in the GBs because of a higher dosage is usually accompanied by segregations at the heterojunction, as observed here. It may lead to secondary phase formation (such as $\mathrm{KInSe}_{2}$ ) on the absorber surface, which emphasizes that interpretation of changes in device performance cannot solely be based on alkali effects at the GBs. It is important to mention that alkali-decorated GBs may have either detrimental or benign effects on the cell efficiency depending on the composition of the GBs, as reported in ref 61. This highlights the complexity of alkali effects in polycrystalline CIGSe (and ACIGSe) and encourages investigating the alkali dispersion in the bulk, at the heterojunction and at the rear-interface simultaneously.

3.3.2. Grain Interiors. Figure 4 shows a plot for the alkali concentrations measured with APT in eight different grains of the CIGSe and ACIGSe samples, and in five different grains of the AIGSe sample. $\mathrm{Na}$ is found to be widely distributed in the GIs, contrary to $\mathrm{K}$, which is more localized at the GBs, especially when a higher dosage of $\mathrm{K}$ is introduced by using HSG, as shown above. These results are consistent with the ion exchange mechanism for alkali elements. ${ }^{22,68}$ The concentration of $\mathrm{Na}$ in the CIGSe reference sample varies from 10 to $20 \mathrm{ppm}$ in the GIs, where the detection limit here in the measurements is $\sim 5 \mathrm{ppm}$. The $\mathrm{Na}$ concentrations in the GIs for CIGSe fit well into the range of values reported from APT measurements in the literature for CIGSe and $\mathrm{CuInSe}_{2}$ (CISe) absorbers. ${ }^{34,36-38}$ Such a consistency implies that $\mathrm{Na}$ reaches a solubility limit in the CIGSe bulk. Exceptional cases can be found in the literature though, such as $148 \mathrm{ppm}$ of $\mathrm{Na}$ in the GIs of CIGSe reported by Choi et al. ${ }^{35}$ using APT. In that case, a fine-structured CIGSe absorber (high defect density) with $\mathrm{Na}$-containing defect clusters in the GIs was examined, which likely contributed to such a high level of $\mathrm{Na}$. It is important to also point out that high alkali content values are sometimes reported for CIGSe using SIMS analysis. ${ }^{21,69}$ This quantification, however, should be treated with caution because SIMS cannot resolve alkali-enriched dislocations, stacking faults, and clustering, even if GBs and GIs are duly separated. These limitations render APT concentrations of alkalis more reliable when resolution of different areas in a microstructure is concerned. It is important to note that significantly fewer decorated defects (such as dislocations) were detected using APT in the GIs of ACIGSe samples compared to the CIGSe sample. The specimen volume analyzed with APT is limited to evaluate defect densities and only decorated defects can be identified, however, these observations may support the arguments of suppressed formation of intragrain defects in ACIGSe. ${ }^{7,70}$
The ACIGSe sample grown on SLG shows a clear increase in the $\mathrm{Na}$ content in the GIs. The $\mathrm{Na}$ concentration in this sample varies between 40 and $60 \mathrm{ppm}$, whereas the $\mathrm{K}$ concentration is below the detection limit. It is important to note here that in the reconstruction shown in Figure $3 b$, it may appear as if some $\mathrm{K}$ is detected in the GIs of this sample. This issue, however, is an artifact, which arises because of a small peak overlap of ${ }^{78} \mathrm{Se}^{2+}$ and ${ }^{39} \mathrm{~K}^{1+}$ at $39 \mathrm{Da}$ in the mass spectrum. Considering the natural isotope abundances, this peak overlap is deconvoluted in calculations of GI compositions and $1 \mathrm{D}$ concentration profiles. For the ACIGSe grown on HSG, $\mathrm{Na}$ concentration varies from 10 to $30 \mathrm{ppm}$ and some GIs show a $\mathrm{K}$ concentration of $\sim 10 \mathrm{ppm}$. APT analysis of the AIGSe (Cu-free) sample grown on SLG revealed even higher $\mathrm{Na}$ concentrations in GIs reaching up to $\sim 200 \mathrm{ppm}$. Fewer grains were possible to examine for the AIGSe sample because of the mechanical instability of the APT specimens during measurements. This is likely stemming from different mechanical properties of the AIGSe absorber (details regarding specimen yield in APT analysis are discussed in ref 71). Hence, all results here point to an increase in the $\mathrm{Na}$ solubility in GIs upon the addition of $\mathrm{Ag}$ in the chalcopyrite absorber. One can expect similar tendencies to exist for heavier alkalis because of similarities in their chemical properties to $\mathrm{Na}$. However, concentrations of heavier alkalis are anticipated to be lower imposed by higher formation energies of alkalirelated point defects in GIs. ${ }^{20}$ The maximum concentration of $\mathrm{Na}$ detected in samples grown on SLG is plotted in Figure 5 to

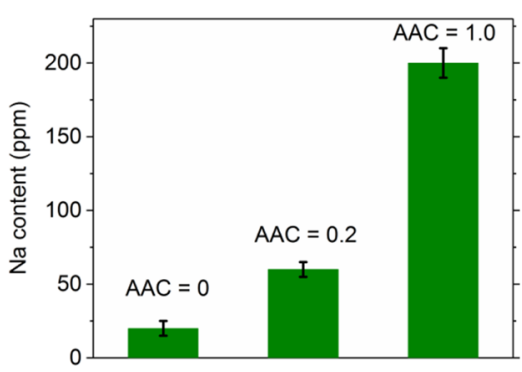

Figure 5. Plot of the highest $\mathrm{Na}$ content measured by APT in each of the three samples grown on SLG with different AAC ratios.

highlight the trend. As discussed in Section 1, the increase in the alkali content is more likely to be of a thermodynamic origin (higher solubility), which is investigated using firstprinciples calculations in the next section.

3.4. Density Functional Theory Calculations. In order to compare the solubilities of alkali elements in ACIGSe and CIGSe, we utilized DFT for computing formation energies of alkali elements on $\mathrm{Cu}$ or $\mathrm{Ag}$ site defects $\left(\mathrm{Alk}_{\mathrm{Cu}}\right.$ and $\left.\mathrm{Alk}_{\mathrm{Ag}}\right)$ as a function of the alloy composition (i.e., GGI and AAC). We only considered the substitutional defects because $\mathrm{Alk}_{\mathrm{Cu}}$ is the most stable alkali-related defect in CIGSe, ${ }^{20}$ and is most likely to remain dominant with addition of Ag. The defect formation energies were computed according to the following equation

$$
\begin{aligned}
H^{\text {form }}\left(\mathrm{Alk}_{\mathrm{I}}\right)= & E_{\text {tot }}\left(\mathrm{Alk}_{\mathrm{I}}\right)-E_{\text {tot }}(\text { bulk })+E_{\text {tot }}\left(\mathrm{I}^{\mathrm{el}}\right) \\
& -E_{\text {tot }}\left(\mathrm{Alk}^{\mathrm{el}}\right)+\Delta \mu_{\mathrm{I}}-\Delta \mu_{\text {Alk }}
\end{aligned}
$$

where $E_{\text {tot }}\left(\mathrm{Alk}_{\mathrm{I}}\right)$ and $E_{\text {tot }}($ bulk) are the total energies of ACIGSe with $\mathrm{Alk}_{\mathrm{Cu}}$ and of the pristine supercell; $E_{\text {tot }}\left(\mathrm{I}^{\mathrm{el}}\right)$ and $E_{\text {tot }}\left(\mathrm{Alk}^{\mathrm{el}}\right)$ are the total energies (per atom) of group-I and Alk elemental ground states; $\Delta \mu_{\mathrm{I}}$ and $\Delta \mu_{\text {Alk }}$ are the chemical 

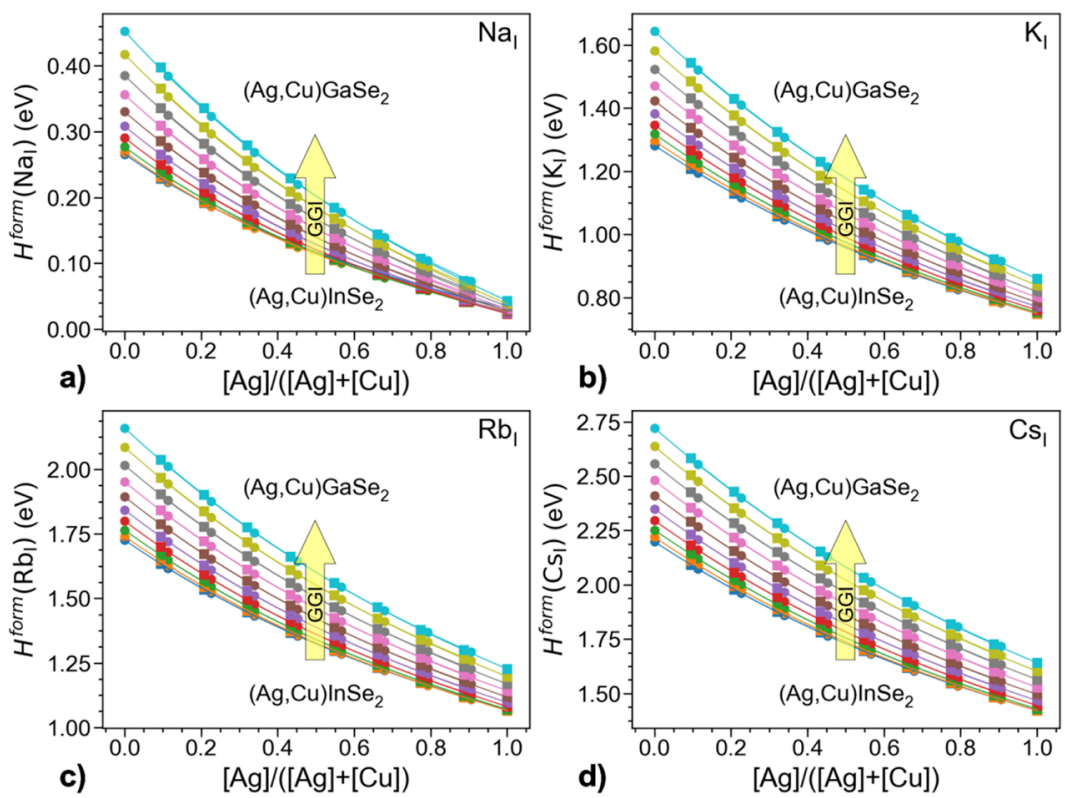

Figure 6. Computed formation energies of $\mathrm{Alk}_{\mathrm{Cu}}$ (circle markers) and $\mathrm{Alk}_{\mathrm{Ag}}$ (square markers) in ACIGSe in equilibrium with the AlkInSe $\mathrm{P}_{2}$ phase for (a) Alk $=\mathrm{Na}$, (b) Alk $=\mathrm{K}$, (c) Alk $=\mathrm{Rb}$, and (d) Alk $=$ Cs. The abscissa gives AAC values for supercells after substitution of the group-I element with the corresponding alkali. The series of curves represent ACIGSe alloys with different GGI values spanning the full range of compositions with equal intervals.

potentials of group-I and Alk species with respect to those in the elemental ground states, respectively. The dependence on the Fermi level and all corrections in eq 1 are omitted because of the charge-neutral nature of $\mathrm{Alk}_{\mathrm{Cu}}$.

To reproduce the stochastic nature of ACIGSe while avoiding large deviations in energies because of the multiplicity of possible cationic arrangements, the total energies of the supercells computed with DFT were processed with the cluster expansion (CE) formalism using the correlation functions of truly random systems. The $\mathrm{CE}$ for an alkali-free alloy was constructed from energies of 100 supercells generated using the SQS algorithm, with compositions spanning the $0 \leq$ GGI $\leq 1$ and $0 \leq \mathrm{AAC} \leq 1$ range and a uniform $10 \times 10$ grid. In a similar manner, CEs for supercells containing defects were constructed for each alkali separately by replacing one randomly selected group-I cation (either $\mathrm{Cu}$ or $\mathrm{Ag}$, whenever applicable) in the alloy supercell (yielding 180 nonequivalent systems). The results obtained without CE processing are given in Supporting Information (see Figure S2) for comparison.

To estimate the chemical potentials of elements in ACIGSe, we utilize the following relation

$$
\begin{aligned}
\Delta H^{\mathrm{f}}(\text { ACIGSe })= & y \cdot \Delta \mu_{\mathrm{Ag}}+(1-y) \cdot \Delta \mu_{\mathrm{Cu}}+x \cdot \Delta \mu_{\mathrm{Ga}} \\
& +(1-x) \cdot \Delta \mu_{\mathrm{In}}+2 \Delta \mu_{\mathrm{Se}}
\end{aligned}
$$

where $x \equiv$ GGI and $y \equiv$ AAC in the equations. Obviously, in contrast with the conventional methodology for defect calculations, ${ }^{72}$ all chemical potentials and ACIGSe formation energy $\left(\Delta H^{\mathrm{f}}(\mathrm{ACIGSe})\right)$ are functions of $(x, y)$ composition. Therefore, nontrivial thermodynamic considerations should be introduced. Herein, we extract an analytical expression for $\Delta H^{\mathrm{f}}(\mathrm{ACIGSe})$ from our earlier study by setting $T=0 \mathrm{~K}$ in the equation for free energy derived within the regular solution approximation. ${ }^{73}$ This knowledge allows relating chemical potentials as

$$
\begin{aligned}
& \frac{\partial \Delta H^{\mathrm{f}}(\text { ACIGSe })}{\partial x}=\Delta \mu_{\mathrm{Ga}}-\Delta \mu_{\mathrm{In}} \\
& \frac{\partial \Delta H^{\mathrm{f}}(\text { ACIGSe })}{\partial y}=\Delta \mu_{\mathrm{Ag}}-\Delta \mu_{\mathrm{Cu}}
\end{aligned}
$$

Combining eqs 2 and 3, one can obtain a system of three equations with five unknowns. The other two free variables can be estimated from the stability diagrams according to the wellestablished formalism for point defect calculations. ${ }^{72}$ Herein, we present the results obtained for equilibrium between the ACIGSe and AlkInSe $e_{2}$ phases. An alternative scenario of equilibrium between ACIGSe and ODC was also explored and discussed in the Supporting Information. Both approximations provide qualitatively similar results, with only one exception specified below.

The choice of equilibrium with AlkInSe ${ }_{2}$ phases is stipulated by the established experimental knowledge. Specifically, formation of $\mathrm{AlkInSe}_{2}$ crystals at CIGSe surfaces after alkali treatments was reported for all four considered alkali elements $\left(\right.$ Alk $=\mathrm{Na}, \mathrm{K}, \mathrm{Rb}$, and Cs). ${ }^{74-77}$ Such crystals are assumed to be nearly $\mathrm{Cu}$-free because AlkInSe $\mathrm{S}_{2}$ exhibits limited miscibility with $\mathrm{CuInSe}_{2},{ }^{74}$ even though Muzzillo et al. $^{78}$ claimed successful synthesis of $(\mathrm{Cu}, \mathrm{K}) \mathrm{InSe}_{2}$ alloys. These factors constitute AlkInSe $\mathrm{A}_{2}$ as a good system for extracting chemical potentials for Ga-poor CIGSe. ${ }^{15,20}$ In ACIGSe, the appearance of $(\mathrm{Ag}, \mathrm{K}) \mathrm{InSe}_{2}$ has been detected after KF PDT in our recent work, ${ }^{26}$ suggesting that a similar approximation can be applied to Ag-alloyed CIGSe. With this in mind, an expression for the formation energy of AlkInSe $e_{2}$ can be written as

$$
\Delta H^{\mathrm{f}}\left(\mathrm{AlkInSe}_{2}\right)=\Delta \mu_{\mathrm{Alk}}+\Delta \mu_{\mathrm{In}}+2 \Delta \mu_{\mathrm{Se}}
$$

which can then be combined with eqs 2 and 3 to yield 

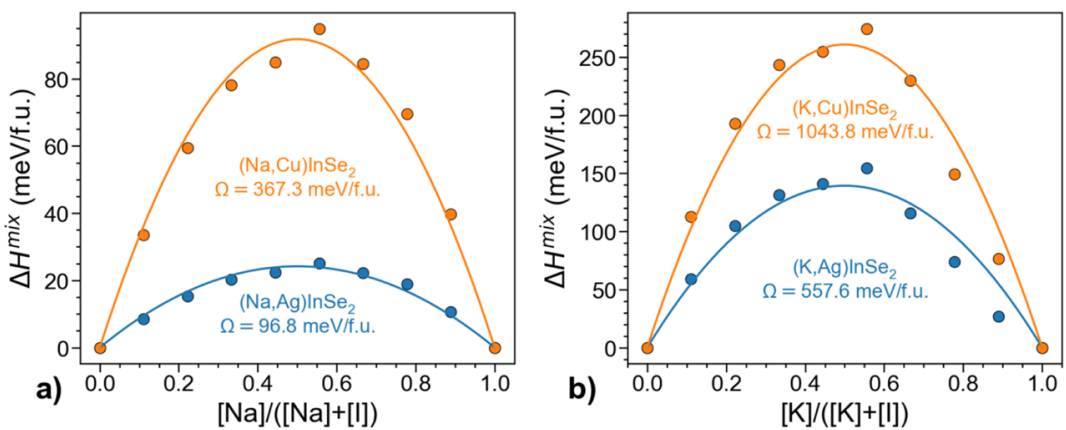

Figure 7. Computed mixing enthalpies for $(\mathrm{Alk}, \mathrm{Cu}) \operatorname{InSe}{ }_{2}$ and $(\mathrm{Alk}, \mathrm{Ag}) \operatorname{InSe} e_{2}$ alloys in the case of $(\mathrm{a}) \mathrm{Alk}=\mathrm{Na}$ and $(\mathrm{b}) \mathrm{Alk}=\mathrm{K}$. The markers and lines represent the computed values and parabolic fits, respectively.

$$
\begin{aligned}
\Delta \mu_{\mathrm{Cu}}-\Delta \mu_{\mathrm{Alk}}= & \Delta H^{\mathrm{f}}(\mathrm{ACIGSe})-\Delta H^{\mathrm{f}}\left(\text { AlkInSe }_{2}\right) \\
& -x \cdot \frac{\partial \Delta H^{\mathrm{f}}(\mathrm{ACIGSe})}{\partial x} \\
& -y \cdot \frac{\partial \Delta H^{f}(\mathrm{ACIGSe})}{\partial y}
\end{aligned}
$$

and eq 5 can then be substituted in eq 1 for the defect formation energy calculations in the case of $\mathrm{Alk}_{\mathrm{Cu}}$. Following the same approach, a similar expression can be deduced for $\Delta \mu_{\mathrm{Ag}}-\Delta \mu_{\mathrm{Alk}}$ and substituted in eq 1 to calculate formation energies of $\mathrm{Alk}_{\mathrm{Ag}}$.

Figure 6 illustrates computed formation energies of $\mathrm{Alk}_{\mathrm{Cu}}$ and $\mathrm{Alk}_{\mathrm{Ag}}$ when ACIGSe is in equilibrium with AlkInSe $\mathrm{A}_{2}$. The first thing to note there is that formation energies of $\mathrm{Alk}_{\mathrm{Cu}}$ and $\mathrm{Alk}_{\mathrm{Ag}}$ follow the same trends. This could be expected because both defects represent the same imperfection in the crystal lattice, $\mathrm{Alk}_{\mathrm{I}}$. In other words, concentration of $\mathrm{Alk}_{\mathrm{I}}$ in the dilute limit is defined by the formation energy, which must be independent of the type of the substituted cation. In fact, the same total energies computed with DFT could be (but were not) used for calculating formation energies of both $\mathrm{Alk}_{\mathrm{Cu}}$ and $\mathrm{Alk}_{\mathrm{Ag}}$ by selecting an appropriate chemical potential $\left(\Delta \mu_{\mathrm{I}}\right)$ for the formally substituted ion and the corresponding energy of the elemental state $\left(E_{\text {tot }}\left(I^{\mathrm{el}}\right)\right)$ in eq 1 . The matching of the formation energies is, therefore, not a material property but a validation of the employed methodology for defect calculations in random alloys.

More importantly, formation energies of all four considered alkalis decrease monotonically with AAC irrespective of GGI, meaning that their solubilities increase with Ag content. These results are in good agreement with our APT findings here and previous studies reporting a higher $\mathrm{Na}$ content in ACIGSe. ${ }^{11,12}$ The formation energy demonstrates a stronger dependence on AAC for heavier alkalis. For instance, the computed difference in energy of $\mathrm{Na}_{\mathrm{I}}$ in $\mathrm{CuInSe}_{2}$ and $\mathrm{AgInSe}_{2}$ is only $0.23 \mathrm{eV}$, whereas the corresponding values for $\mathrm{K}_{\mathrm{I}}, \mathrm{Rb}_{\mathrm{I}}$, and $\mathrm{Cs}_{\mathrm{I}}$ are 0.53 , 0.66 , and $0.78 \mathrm{eV}$, respectively. As for the absolute values, heavier alkalis have much higher formation energies (lower solubilities), which is explained by the larger ions inflicting more stress on the lattice. ${ }^{20}$ This is probably also the reason why we did not detect any considerable $\mathrm{K}$ content in GIs with $\mathrm{APT}$, as it had probably diffused into the GBs during cooling. At the same time, despite the decrease in formation energies upon Ag alloying, the solubility for Rb and Cs in GIs would possibly remain below the detection limit of APT if the absorbers were treated with $\mathrm{Rb}$ or Cs PDT. As such, charge- neutral $\mathrm{Rb}_{\mathrm{I}}$ and $\mathrm{Cs}_{\mathrm{I}}$ are expected to play practically no role in properties of bulk ACIGSe.

The formation energies increase slightly (but consistently) with GGI. This dependence is weaker compared to that on AAC and thus should be treated with more caution. This trend might even be invisible against random variations under the growth conditions, and hence, we did not attempt to verify it experimentally. The sensitivity of this result is evident, for instance, as the formation energy of $\mathrm{Na}_{\mathrm{Ag}}$ increases slightly with GGI when $\mathrm{Ag}(\mathrm{Ga}, \mathrm{In}) \mathrm{Se}_{2}$ is in equilibrium with $\mathrm{AlkInSe}_{2}$ but decreases when an alternative approach assuming equilibrium with ODC is considered (see Supporting Information). Such a behavior is not surprising because the equilibrium with $\mathrm{AlkInSe}_{2}$ compounds is, strictly speaking, inapplicable to Ga-rich systems because other Alk containing Ga-rich phases would segregate in those systems instead. Despite this limitation, the computed dependences on AAC are not strongly affected by the assumed equilibrium, suggesting that both approximations are able to reasonably reproduce the actual chemistry of the alloy.

The computed energies can be used to estimate the ratio of equilibrium $\mathrm{Na}_{\mathrm{I}}$ concentrations in ACIGSe and CIGSe as

$$
\frac{C_{\mathrm{ACIGSe}}\left(\mathrm{Na}_{\mathrm{I}}\right)}{C_{\mathrm{CIGSe}}\left(\mathrm{Na}_{\mathrm{I}}\right)}=\exp \left(\frac{H_{\mathrm{CIGSe}}^{\text {form }}\left(\mathrm{Na}_{\mathrm{I}}\right)-H_{\mathrm{ACIGSe}}^{\text {form }}\left(\mathrm{Na}_{\mathrm{I}}\right)}{k_{\mathrm{B}} T}\right)
$$

Assuming equilibration during $\mathrm{PDT}$ at $350^{\circ} \mathrm{C}$, the estimated $\mathrm{Na}$ concentrations in ACIGSe with GGI $=0.3$ and AAC of 0.2, 0.5 , and 1.0 are roughly 4,17 , and 120 times higher than in CIGSe, respectively. Importantly, the predicted four-fold increase in the $\mathrm{Na}$ content for $\mathrm{AAC}=0.2$ is not far from our chemical quantifications of GIs using APT. The value for $\mathrm{AAC}=0.5$ is also in reasonable agreement with one order-ofmagnitude higher $\mathrm{Na}$ content measured with SIMS in the top ACIGSe cell of the tandem device fabricated by Kim et al., ${ }^{12}$ but is lower than that reported in their earlier work, ${ }^{11}$ possibly because of the presence of impurity phases and/or variations under the growth conditions. In contrast, the predicted increase in the $\mathrm{Na}$ concentration for $\mathrm{AAC}=1.0$ does not match the $\sim 10$ times higher $\mathrm{Na}$ content from our APT measurements on the $\mathrm{Cu}$-free reference sample (see Figure 5), although the trend is correct on a qualitative level. A likely explanation for the discrepancy is that the maximum solubility is not reached during processing for this sample because much greater amount of $\mathrm{Na}$ from the substrate is required to saturate the absorber. Further analysis of this hypothesis from the perspective of alloy formation rather than the dilute limit approximation is provided below. 
The observed trends in solubility versus AAC can be explained by a mismatch of ionic sizes of the group-I cations and alkali impurities. According to Shannon, ${ }^{79}$ crystal ionic radii of four-coordinated ions are $1.13 \AA$ for $\mathrm{Na}^{1+}, 1.51 \AA$ for $\mathrm{K}^{1+}, 0.74 \AA$ for $\mathrm{Cu}^{1+}$, and $1.14 \AA$ for $\mathrm{Ag}^{1+}$. As one can see, the $\mathrm{Na}^{1+}$ ion is considerably larger than $\mathrm{Cu}^{1+}$ but of the same size as $\mathrm{Ag}^{1+}$, suggesting that $\mathrm{Alk}_{\mathrm{I}}$ induces less stress on the lattice and thus has lower formation energy (on average) in Ag-rich ACIGSe. The size mismatch increases for heavier alkalis, but it always remains smaller in Ag-based systems, resulting in a general tendency of increasing solubility with AAC.

To further explore the role of lattice stress and consider the alkali incorporation beyond the dilute limit, we also computed mixing enthalpies of $(\mathrm{Na}, \mathrm{Ag}) \mathrm{InSe}_{2},(\mathrm{Na}, \mathrm{Cu}) \mathrm{InSe}_{2},(\mathrm{~K}, \mathrm{Ag})$ $\mathrm{InSe}_{2}$, and $(\mathrm{K}, \mathrm{Cu}) \mathrm{InSe}_{2}$ alloys as

$$
\begin{aligned}
\Delta H^{\text {mix }}= & E_{\text {tot }}\left(\operatorname{Alk}_{x} \mathrm{Ag}_{1-x} \operatorname{InSe}_{2}\right)-x \cdot E_{\text {tot }}\left(\operatorname{AlkInSe}_{2}\right) \\
& -(1-x) \cdot E_{\text {tot }}\left(\mathrm{AgInSe}_{2}\right)
\end{aligned}
$$

where $E_{\text {tot }}$ represents computed total energies for supercells of different compositions. The Ga-based alloys were not considered because of the lack of structural information on $\mathrm{NaGaSe}_{2}$ in the literature, which might be a sign of its instability. The alloy interaction (bowing) parameters for mixing enthalpies were extracted from parabolic fits to the computed energy values, as shown in Figure 7. Furthermore, the consolute temperatures (the points at which the alloys become fully miscible) were estimated from a regular solution approximation as $T_{\mathrm{c}}=\Omega / 2 k_{\mathrm{B}}$. The obtained interaction parameters $\Omega$ for the respective systems are $96.8,367.3,557.6$, and $1043.8 \mathrm{meV} /$ f.u. (per formula unit), which yield consolute temperatures of $288,1858,2962$, and $5783{ }^{\circ} \mathrm{C}$, in agreement with the earlier results for $\mathrm{Cu}$-based chalcopyrites. ${ }^{15}$ As expected, the mixing enthalpies are lower in Ag-based systems because of the aforementioned smaller ionic size mismatch. This tendency was also observed for $\mathrm{Rb}$ and $\mathrm{Cs}$, but the corresponding mixing parameters are not extracted because of severe relaxation experienced by the alkali-rich supercells. These consolute temperatures for all except ( $\mathrm{Na}, \mathrm{Ag}) \mathrm{InSe}_{2}$ alloys are beyond the reach of synthesis as the chalcopyrite systems melt at lower temperatures. ${ }^{80}$ As such, the wide miscibility gap during processing clearly limits alkali solubility for most systems. However, the exception of $(\mathrm{Na}, \mathrm{Ag}) \mathrm{InSe}_{2}$ means that this alloy can form during absorber deposition (550 ${ }^{\circ} \mathrm{C}$ ) as well as during the $\operatorname{PDT}\left(350{ }^{\circ} \mathrm{C}\right)$. Practically, it means that the solubility of $\mathrm{Na}$ in $\mathrm{AgInSe}_{2}$ absorbers is not thermodynamically limited but instead governed by the processing parameters (primarily time and temperature because of the thermally activated nature of $\mathrm{Na}$ in-diffusion from the substrate), as we hypothesized above. Considering that the dependence of $\mathrm{Na}_{\mathrm{I}}$ formation energy on GGI (see Figure 6a) is weak, this conclusion can also be generalized to all AIGSe alloys, thereby explaining why the increase in the $\mathrm{Na}$ concentration in the $\mathrm{Cu}$-free reference AIGSe sample deduced from the APT analysis was below the predicted equilibrium value.

\section{CONCLUSIONS}

In this work, we studied the relationship of $\mathrm{Ag}$ alloying in CIGSe on the alkali dispersion in bulk and at interfaces to better understand the enhancements in device performance related to the addition of Ag. Experimental analysis is performed for ACIGSe absorbers deposited on two different
(K- and Na-rich) glass substrate types. The ion exchange mechanism commonly discussed in the literature for light and heavy alkali elements in CIGSe is observed for $\mathrm{Na}$ and $\mathrm{K}$ distributions in GBs and GIs. Alkali segregations at the CdS/ ACIGSe and rear interfaces, as well as in the GBs, were detected. $\mathrm{K}$ segregation appears to dominate over $\mathrm{Na}$ at the GBs in CIGSe and ACIGSe. While this behavior can be expected with the HSG substrate, simply because more $\mathrm{K}$ is supplied, stronger $\mathrm{Na}$ segregations would be expected when using the SLG substrate if not for the ion exchange mechanism. At the same time, GIs contain greater concentrations of $\mathrm{Na}$ than $\mathrm{K}$, even for the absorber grown on the HSG substrate. This indicates higher solubility of $\mathrm{Na}$ in GIs compared to $\mathrm{K}$. Furthermore, it is found that the $\mathrm{Na}$ concentration in the GIs increases with Ag-alloying. The nanoscale experimental analysis was combined with first-principles calculations, providing strong indications of increased solubility of alkali elements in GIs of ACIGSe compared to CIGSe. Such a behavior stems from a mismatch of ionic sizes of group-I cations and alkali impurities, with $\mathrm{Na}^{1+}$ ions, for instance, being similar in size to $\mathrm{Ag}^{1+}$ but considerably larger than $\mathrm{Cu}^{1+}$, and hence, inflicting less stress upon formation of $\mathrm{Na}_{\mathrm{I}}$ in Ag-alloyed CIGSe. The same rationale applied to heavier alkali elements as well. Hence, an increase in $V_{\mathrm{OC}}$ of CIGSe devices with the addition of $\mathrm{Ag}$ can be related to higher acceptance of alkali elements in the matrix, as well as improved band alignments and/or other factors discussed earlier. The fundamental difference in alkali dispersion demonstrated here for Agalloyed CIGSe absorbers should be taken into consideration when designing optimized alkali treatments in single- or multiple-junction solar cells using these types of absorbers.

\section{ASSOCIATED CONTENT}

\section{SI Supporting Information}

The Supporting Information is available free of charge at https://pubs.acs.org/doi/10.1021/acsami.0c20539.

Local chemical analysis of the CdS/ACIGSe interface; as-computed formation energies of $\mathrm{Alk}_{\mathrm{I}}$ in ACIGSe supercells without additional processing with the $\mathrm{CE}$ formalism; defect formation energies assuming equilibrium between $(\mathrm{Ag}, \mathrm{Cu})(\mathrm{In}, \mathrm{Ga})_{3} \mathrm{Se}_{5}$ and ACIGSe with the same AAC and GGI ratios; and primitive cell used for simulation of $(\mathrm{Ag}, \mathrm{Cu})(\mathrm{In}, \mathrm{Ga})_{3} \mathrm{Se}_{5}$ (in CIF format) (PDF)

\section{AUTHOR INFORMATION}

\section{Corresponding Author}

Hisham Aboulfadl - Division of Microstructure Physics, Department of Physics, Chalmers University of Technology, 41296 Göteborg, Sweden; (1) orcid.org/0000-0003-2651482X; Email: hisham.aboulfadl@chalmers.se

\section{Authors}

Kostiantyn V. Sopiha - Division of Solar Cell Technology, Department of Materials Science and Engineering, Uppsala University, 75121 Uppsala, Sweden

Jan Keller - Division of Solar Cell Technology, Department of Materials Science and Engineering, Uppsala University, 75121 Uppsala, Sweden

Jes K. Larsen - Division of Solar Cell Technology, Department of Materials Science and Engineering, Uppsala University, 
75121 Uppsala, Sweden; 다이.org/0000-0002-73924701

Jonathan J.S. Scragg - Division of Solar Cell Technology, Department of Materials Science and Engineering, Uppsala University, 75121 Uppsala, Sweden; ㅇo이.org/00000001-8686-8721

Clas Persson - Center of Materials Science and Nanotechnology, Department of Physics, University of Oslo, 0316 Oslo, Norway; Division of Applied Materials Physics, Department of Materials Science and Engineering, KTH Royal Institute of Technology, 10044 Stockholm, Sweden; (i) orcid.org/0000-0002-9050-5445

Mattias Thuvander - Division of Microstructure Physics, Department of Physics, Chalmers University of Technology, 41296 Göteborg, Sweden

Marika Edoff - Division of Solar Cell Technology, Department of Materials Science and Engineering, Uppsala University, 75121 Uppsala, Sweden

Complete contact information is available at: https://pubs.acs.org/10.1021/acsami.0c20539

\section{Funding}

Swedish Foundation for Strategic Research, grant/award number: RMA15-0030.

\section{Notes}

The authors declare no competing financial interest.

\section{ACKNOWLEDGMENTS}

The computations and data handling were enabled by resources provided by the Swedish National Infrastructure for Computing (SNIC) at National Supercomputing Center (NSC) at Linköping University and PDC Center for High Performance Computing at KTH Royal Institute of Technology (projects: 2019/3-537 and 2019-3-381) partially funded by the Swedish Research Council through grant agreement no. 2018-05973.

\section{REFERENCES}

(1) Ramanujam, J.; Singh, U. P. Copper Indium Gallium Selenide Based Solar Cells - a Review. Energy Environ. Sci. 2017, 10, 13061319.

(2) Guillemoles, J. F. The Puzzle of $\mathrm{Cu}(\mathrm{In}, \mathrm{Ga}) \mathrm{Se}_{2}$ (CIGS) Solar Cells Stability. Thin Solid Films 2002, 403-404, 405-409.

(3) Gloeckler, M.; Sites, J. R. Band-Gap Grading in $\mathrm{Cu}(\mathrm{In}, \mathrm{Ga}) \mathrm{Se} 2$ Solar Cells. J. Phys. Chem. Solids 2005, 66, 1891-1894.

(4) Powalla, M.; Paetel, S.; Ahlswede, E.; Wuerz, R.; Wessendorf, C. D.; Magorian Friedlmeier, T. Thin-Film Solar Cells Exceeding 22\% Solar Cell Efficiency: An Overview on CdTe-, $\mathrm{Cu}(\mathrm{In}, \mathrm{Ga}) \mathrm{Se}_{2}$, , and Perovskite-Based Materials. Appl. Phys. Rev. 2018, 5, 041602.

(5) Wei, S. H.; Zunger, A. Band Offsets and Optical Bowings of Chalcopyrites and Zn-Based II-VI Alloys. J. Appl. Phys. 1995, 78, 3846-3856.

(6) Hanket, G. M.; Boyle, J. H.; Shafarman, W. N. Characterization and Device Performance of $(\mathrm{AgCu})(\mathrm{InGa})_{2}$ Absorber Layers. 2009 34th IEEE Photovoltaics Specialists Conference, Philadelphia, PA, 2009; pp 001240-001245.

(7) Boyle, J. H.; McCandless, B. E.; Shafarman, W. N.; Birkmire, R. W. Structural and Optical Properties of $(\mathrm{Ag}, \mathrm{Cu})(\mathrm{In}, \mathrm{Ga}) \mathrm{Se}_{2}$ Polycrystalline Thin Film Alloys. J. Appl. Phys. 2014, 115, 223504.

(8) Keller, J.; Sopiha, K. V.; Stolt, O.; Stolt, L.; Persson, C.; Scragg, J. J. S.; Törndahl, T.; Edoff, M. Wide-Gap $(\mathrm{Ag}, \mathrm{Cu})(\mathrm{In}, \mathrm{Ga}) \mathrm{Se}_{2}$ Solar Cells with Different Buffer Materials - A Path to a Better Heterojunction. Prog. Photovoltaics 2020, 28, 237-250.
(9) Shafarman, W.; Thompson, C.; Boyle, J.; Hanket, G.; Erslev, P.; Cohen, J. D. Device Characterization of $(\mathrm{AgCu})(\mathrm{InGa}) \mathrm{Se}_{2}$ Solar Cells. 2010 35th IEEE Photovoltaics Specialists Conference, Honolulu, HI, 2010; pp 325-329.

(10) Edoff, M.; Jarmar, T.; Nilsson, N. S.; Wallin, E.; Hogstrom, D.; Stolt, O.; Lundberg, O.; Shafarman, W.; Stolt, L. High VOC in $(\mathrm{Cu}, \mathrm{Ag})(\mathrm{In}, \mathrm{Ga}) \mathrm{Se} 2$ Solar Cells. IEEE J. Photovoltaics 2017, 7, 17891794.

(11) Kim, K.; Park, J. W.; Yoo, J. S.; Cho, J.-s.; Lee, H.-D.; Yun, J. H. $\mathrm{Ag}$ Incorporation in Low-Temperature Grown $\mathrm{Cu}(\mathrm{In}, \mathrm{Ga}) \mathrm{Se}_{2}$ Solar Cells Using Ag Precursor Layers. Sol. Energy Mater. Sol. Cells 2016, 146, 114-120.

(12) Kim, K.; Ahn, S. K.; Choi, J. H.; Yoo, J.; Eo, Y.-J.; Cho, J.-S.; Cho, A.; Gwak, J.; Song, S.; Cho, D.-H.; Chung, Y.-D.; Yun, J. H. Highly Efficient Ag-Alloyed $\mathrm{Cu}(\mathrm{In}, \mathrm{Ga}) \mathrm{Se}_{2}$ Solar Cells with Wide Bandgaps and Their Application to Chalcopyrite-Based Tandem Solar Cells. Nano Energy 2018, 48, 345-352.

(13) Chen, L.; Lee, J.; Shafarman, W. N. The Comparison of $(\mathrm{Ag}, \mathrm{Cu})(\mathrm{In}, \mathrm{Ga}) \mathrm{Se}_{2}$ and $\mathrm{Cu}(\mathrm{In}, \mathrm{Ga}) \mathrm{Se} 2$ Thin Films Deposited by Three-Stage Coevaporation. IEEE J. Photovoltaics 2014, 4, 447-451.

(14) Sun, Y.; Lin, S.; Li, W.; Cheng, S.; Zhang, Y.; Liu, Y.; Liu, W. Review on Alkali Element Doping in $\mathrm{Cu}(\mathrm{In}, \mathrm{Ga}) \mathrm{Se}_{2}$ Thin Films and Solar Cells. Engineering 2017, 3, 452-459.

(15) Siebentritt, S.; Avancini, E.; Bär, M.; Bombsch, J.; Bourgeois, E.; Buecheler, S.; Carron, R.; Castro, C.; Duguay, S.; Félix, R.; Handick, E.; Hariskos, D.; Havu, V.; Jackson, P.; Komsa, H. P.; Kunze, T.; Malitckaya, M.; Menozzi, R.; Nesladek, M.; Nicoara, N.; Puska, M.; Raghuwanshi, M.; Pareige, P.; Sadewasser, S.; Sozzi, G.; Tiwari, A. N.; Ueda, S.; Vilalta-Clemente, A.; Weiss, T. P.; Werner, F.; Wilks, R. G.; Witte, W.; Wolter, M. H. Heavy Alkali Treatment of $\mathrm{Cu}(\mathrm{In}, \mathrm{Ga}) \mathrm{Se}_{2}$ Solar Cells: Surface versus Bulk Effects. Adv. Energy Mater. 2020, 10, 1903752.

(16) Granath, K.; Bodegård, M.; Stolt, L. Effect of NaF on $\mathrm{Cu}(\mathrm{In}, \mathrm{Ga}) \mathrm{Se}_{2}$ Thin Film Solar Cells. Sol. Energy Mater. Sol. Cells 2000, 60, 279-293.

(17) Ruckh, M.; Schmid, D.; Kaiser, M.; Schäffler, R.; Walter, T.; Schock, H. Influence of Substrates on the Electrical Properties of $\mathrm{Cu}(\mathrm{In}, \mathrm{Ga}) \mathrm{Se}_{2}$ Thin Films. Sol. Energy Mater. Sol. Cells 1996, 41-42, 335-343.

(18) Kronik, L.; Cahen, D.; Schock, H. W. Effects of Sodium on Polycrystalline $\mathrm{Cu}(\mathrm{In}, \mathrm{Ga}) \mathrm{Se}_{2}$ and Its Solar Cell Performance. Adv. Mater. 1998, 10, 31-36.

(19) Muzzillo, C. P.; Poplawsky, J. D.; Tong, H. M.; Guo, W.; Anderson, T. Revealing the Beneficial Role of $\mathrm{K}$ in Grain Interiors, Grain Boundaries, and at the Buffer Interface for Highly Efficient $\mathrm{CuInSe}_{2}$ Solar Cells. Prog. Photovoltaics 2018, 26, 825-834.

(20) Malitckaya, M.; Komsa, H.-P.; Havu, V.; Puska, M. J. Effect of Alkali Metal Atom Doping on the CuInSe ${ }_{2}$-Based Solar Cell Absorber. J. Phys. Chem. C 2017, 121, 15516-15528.

(21) Wuerz, R.; Hempel, W.; Jackson, P. Diffusion of Rb in Polycrystalline $\mathrm{Cu}(\mathrm{In}, \mathrm{Ga}) \mathrm{Se}_{2}$ Layers and Effect of $\mathrm{Rb}$ on Solar Cell Parameters of $\mathrm{Cu}(\mathrm{In}, \mathrm{Ga}) \mathrm{Se}_{2}$ Thin-Film Solar Cells. J. Appl. Phys. 2018, 124, 165305.

(22) Muzzillo, C. P. Review of Grain Interior, Grain Boundary, and Interface Effects of $\mathrm{K}$ in CIGS Solar Cells: Mechanisms for Performance Enhancement. Sol. Energy Mater. Sol. Cells 2017, 172, $18-24$.

(23) Yuan, Z.-K.; Chen, S.; Xie, Y.; Park, J.-S.; Xiang, H.; Gong, X.G.; Wei, S.-H. Na-Diffusion Enhanced p-Type Conductivity in $\mathrm{Cu}(\mathrm{In}, \mathrm{Ga}) \mathrm{Se}_{2}$ : A New Mechanism for Efficient Doping in Semiconductors. Adv. Energy Mater. 2016, 6, 1601191.

(24) Pianezzi, F.; Reinhard, P.; Chirilă, A.; Bissig, B.; Nishiwaki, S.; Buecheler, S.; Tiwari, A. N. Unveiling the Effects of Post-Deposition Treatment with Different Alkaline Elements on the Electronic Properties of CIGS Thin Film Solar Cells. Phys. Chem. Chem. Phys. 2014, 16, 8843-8851.

(25) Urbaniak, A.; Igalson, M.; Pianezzi, F.; Bücheler, S.; Chirilă, A.; Reinhard, P.; Tiwari, A. N. Effects of Na Incorporation on Electrical 
Properties of $\mathrm{Cu}(\mathrm{In}, \mathrm{Ga}) \mathrm{Se}_{2}$-Based Photovoltaic Devices on Polyimide Substrates. Sol. Energy Mater. Sol. Cells 2014, 128, 52-56.

(26) Donzel-Gargand, O.; Larsson, F.; Törndahl, T.; Stolt, L.; Edoff, M. Secondary Phase Formation and Surface Modification from a High Dose KF-Post Deposition Treatment of $(\mathrm{Ag}, \mathrm{Cu})(\mathrm{In}, \mathrm{Ga}) \mathrm{Se}_{2}$ Solar Cell Absorbers. Prog. Photovoltaics 2019, 27, 220-228.

(27) Larsson, F.; Donzel-Gargand, O.; Keller, J.; Edoff, M.; Törndahl, T. Atomic Layer Deposition of $\mathrm{Zn}(\mathrm{O}, \mathrm{S})$ Buffer Layers for $\mathrm{Cu}(\mathrm{In}, \mathrm{Ga}) \mathrm{Se}_{2}$ Solar Cells with KF Post-Deposition Treatment. Sol. Energy Mater. Sol. Cells 2018, 183, 8-15.

(28) Feurer, T.; Fu, F.; Weiss, T. P.; Avancini, E.; Löckinger, J.; Buecheler, S.; Tiwari, A. N. RbF Post Deposition Treatment for Narrow Bandgap $\mathrm{Cu}(\mathrm{In}, \mathrm{Ga}) \mathrm{Se}_{2}$ Solar Cells. Thin Solid Films 2019, 670, 34-40.

(29) Caballero, R.; Kaufmann, C. A.; Eisenbarth, T.; Unold, T.; Klenk, R.; Schock, H.-W. High Efficiency Low Temperature Grown $\mathrm{Cu}(\mathrm{In}, \mathrm{Ga}) \mathrm{Se}_{2}$ Thin Film Solar Cells on Flexible Substrates Using NaF Precursor Layers. Prog. Photovoltaics 2011, 19, 547-551.

(30) Valdes, N. H.; Jones, K. J.; Opila, R. L.; Shafarman, W. N. Influence of $\mathrm{Ga}$ and $\mathrm{Ag}$ on the KF Treatment Chemistry for CIGS Solar Cells. IEEE J. Photovoltaics 2019, 9, 1846-1851.

(31) Valdes, N. H.; Lee, J.; Shafarman, W. N. Ag Alloying and KF Treatment Effects on Low Bandgap CuInSe2 Solar Cells. IEEE J. Photovoltaics 2019, 9, 906-911.

(32) Raghuwanshi, M.; Thöner, B.; Soni, P.; Wuttig, M.; Wuerz, R.; Cojocaru-Mirédin, O. Evidence of Enhanced Carrier Collection in $\mathrm{Cu}(\mathrm{In}, \mathrm{Ga}) \mathrm{Se}_{2}$ Grain Boundaries: Correlation with Microstructure. ACS Appl. Mater. Interfaces 2018, 10, 14759-14766.

(33) Schwarz, T.; Stechmann, G.; Gault, B.; Cojocaru-Miredin, O.; Choi, P.; Redinger, A.; Siebentritt, S.; Raabe, D. Correlative Transmission EBSD-APT Analysis of Grain Boundaries in $\mathrm{Cu}-$ (In,Ga)Se2 and Cu2ZnSnSe4 Based Thin-Film Solar Cells. Microsc. Microanal. 2017, 23, 672-673.

(34) Colombara, D.; Werner, F.; Schwarz, T.; Cañero Infante, I.; Fleming, Y.; Valle, N.; Spindler, C.; Vacchieri, E.; Rey, G.; Guennou, M.; Bouttemy, M.; Manjón, A. G.; Peral Alonso, I.; Melchiorre, M.; El Adib, B.; Gault, B.; Raabe, D.; Dale, P. J.; Siebentritt, S. Sodium Enhances Indium-Gallium Interdiffusion in Copper Indium Gallium Diselenide Photovoltaic Absorbers. Nat. Commun. 2018, 9, 826.

(35) Choi, P.-P.; Cojocaru-Mirédin, O.; Wuerz, R.; Raabe, D. Comparative Atom Probe Study of $\mathrm{Cu}(\mathrm{In}, \mathrm{Ga}) \mathrm{Se} 2$ Thin-Film Solar Cells Deposited on Soda-Lime Glass and Mild Steel Substrates. J. Appl. Phys. 2011, 110, 124513.

(36) Keller, J.; Schlesiger, R.; Riedel, I.; Parisi, J.; Schmitz, G.; Avellan, A.; Dalibor, T. Grain Boundary Investigations on Sulfurized $\mathrm{Cu}(\mathrm{In}, \mathrm{Ga})(\mathrm{S}, \mathrm{Se})_{2}$ Solar Cells Using Atom Probe Tomography. Sol. Energy Mater. Sol. Cells 2013, 117, 592-598.

(37) Cojocaru-Mirédin, O.; Choi, P.; Wuerz, R.; Raabe, D. AtomicScale Distribution of Impurities in CuInSe2-Based Thin-Film Solar Cells. Ultramicroscopy 2011, 111, 552-556.

(38) Vilalta-Clemente, A.; Raghuwanshi, M.; Duguay, S.; Castro, C.; Cadel, E.; Pareige, P.; Jackson, P.; Wuerz, R.; Hariskos, D.; Witte, W. Rubidium Distribution at Atomic Scale in High Efficient $\mathrm{Cu}(\mathrm{In}, \mathrm{Ga})$ $\mathrm{Se}_{2}$ Thin-Film Solar Cells. Appl. Phys. Lett. 2018, 112, 103105.

(39) Cojocaru-Mirédin, O.; Choi, P.-P.; Abou-Ras, D.; Schmidt, S. S.; Caballero, R.; Raabe, D. Characterization of Grain Boundaries in $\mathrm{Cu}(\mathrm{In}, \mathrm{Ga}) \mathrm{Se}_{2}$ Films Using Atom-Probe Tomography. IEEE J. Photovoltaics 2011, 1, 207-212.

(40) Cojocaru-Mirédin, O.; Schwarz, T.; Abou-Ras, D. Assessment of Elemental Distributions at Line and Planar Defects in $\mathrm{Cu}(\mathrm{In}, \mathrm{Ga})$ $\mathrm{Se}_{2}$ Thin Films by Atom Probe Tomography. Scr. Mater. 2018, 148, $106-114$.

(41) Cadel, E.; Barreau, N.; Kessler, J.; Pareige, P. Atom Probe Study of Sodium Distribution in Polycrystalline $\mathrm{Cu}$ (In,Ga)Se $\mathrm{S}_{2}$ Thin Film. Acta Mater. 2010, 58, 2634-2637.

(42) Stokes, A.; Al-Jassim, M.; Diercks, D.; Clarke, A.; Gorman, B. Impact of Wide-Ranging Nanoscale Chemistry on Band Structure at $\mathrm{Cu}(\mathrm{In}, \mathrm{Ga}) \mathrm{Se}_{2}$ Grain Boundaries. Sci. Rep. 2017, 7, 14163.
(43) Laemmle, A.; Wuerz, R.; Schwarz, T.; Cojocaru-Mirédin, O.; Choi, P.-P.; Powalla, M. Investigation of the Diffusion Behavior of Sodium in $\mathrm{Cu}(\mathrm{In}, \mathrm{Ga}) \mathrm{Se}_{2}$ Layers. J. Appl. Phys. 2014, 115, 154501.

(44) Stokes, A.; Al-Jassim, M.; Norman, A.; Diercks, D.; Gorman, B. Nanoscale Insight into the P-n Junction of Alkali-Incorporated $\mathrm{Cu}(\mathrm{In}, \mathrm{Ga}) \mathrm{Se}_{2}$ Solar Cells. Prog. Photovoltaics 2017, 25, 764-772.

(45) Cojocaru-Mirédin, O.; Schwarz, T.; Choi, P.-P.; Herbig, M.; Wuerz, R.; Raabe, D. Atom Probe Tomography Studies on the $\mathrm{Cu}(\mathrm{In}, \mathrm{Ga}) \mathrm{Se}_{2}$ Grain Boundaries. J. Visualized Exp. 2013, 74, 50376.

(46) Thompson, K.; Lawrence, D.; Larson, D. J.; Olson, J. D.; Kelly, T. F.; Gorman, B. In Situ Site-Specific Specimen Preparation for Atom Probe Tomography. Ultramicroscopy 2007, 107, 131-139.

(47) Kresse, G.; Furthmüller, J. Efficiency of Ab-Initio Total Energy Calculations for Metals and Semiconductors Using a Plane-Wave Basis Set. Comput. Mater. Sci. 1996, 6, 15-50.

(48) Kresse, G.; Furthmüller, J. Efficient Iterative Schemes for Ab Initio Total-Energy Calculations Using a Plane-Wave Basis Set. Phys. Rev. B: Condens. Matter Mater. Phys. 1996, 54, 11169-11186.

(49) Kresse, G.; Hafner, J. Ab Initio Molecular Dynamics for Liquid Metals. Phys. Rev. B: Condens. Matter Mater. Phys. 1993, 47, 558-561.

(50) Kresse, G.; Joubert, D. From Ultrasoft Pseudopotentials to the Projector Augmented-Wave Method. Phys. Rev. B: Condens. Matter Mater. Phys. 1999, 59, 1758-1775.

(51) Blöchl, P. E. Projector Augmented-Wave Method. Phys. Rev. B: Condens. Matter Mater. Phys. 1994, 50, 17953-17979.

(52) Perdew, J. P.; Burke, K.; Ernzerhof, M. Generalized Gradient Approximation Made Simple. Phys. Rev. Lett. 1996, 77, 3865-3868.

(53) Zunger, A.; Wei, S.-H.; Ferreira, L. G.; Bernard, J. E. Special Quasirandom Structures. Comput. Mater. Sci. 1990, 65, 353-356.

(54) Van De Walle, A.; Tiwary, P.; De Jong, M.; Olmsted, D. L.; Asta, M.; Dick, A.; Shin, D.; Wang, Y.; Chen, L.-Q.; Liu, Z.-K. Efficient Stochastic Generation of Special Quasirandom Structures. CALPHAD: Comput. Coupling Phase Diagrams Thermochem. 2013, 42, $13-18$.

(55) Chadi, D. J. Special Points for Brillouin-Zone Integrations. Phys. Rev. B: Solid State 1977, 16, 1746-1747.

(56) Ong, S. P.; Richards, W. D.; Jain, A.; Hautier, G.; Kocher, M.; Cholia, S.; Gunter, D.; Chevrier, V. L.; Persson, K. A.; Ceder, G. Python Materials Genomics (Pymatgen): A Robust, Open-Source Python Library for Materials Analysis. Comput. Mater. Sci. 2013, 68, 314-319.

(57) Keller, J.; Stolt, L.; Sopiha, K. V.; Larsen, J. K.; Riekehr, L.; Edoff, M. On the Paramount Role of Absorber Stoichiometry in $(\mathrm{Ag}, \mathrm{Cu})(\mathrm{In}, \mathrm{Ga}) \mathrm{Se}_{2}$ Wide-Gap Solar Cells. Sol. RRL 2020, 4, 2000508.

(58) Ümsür, B.; Calvet, W.; Steigert, A.; Lauermann, I.; Gorgoi, M.; Prietzel, K.; Greiner, D.; Kaufmann, C. A.; Unold, T.; Lux-Steiner, M. C. Investigation of the Potassium Fluoride Post Deposition Treatment on the CIGSe/CdS Interface Using Hard X-Ray Photoemission Spectroscopy-a Comparative Study. Phys. Chem. Chem. Phys. 2016, 18, 14129-14138.

(59) Handick, E.; Reinhard, P.; Wilks, R. G.; Pianezzi, F.; Kunze, T.; Kreikemeyer-Lorenzo, D.; Weinhardt, L.; Blum, M.; Yang, W.; Gorgoi, M.; Ikenaga, E.; Gerlach, D.; Ueda, S.; Yamashita, Y.; Chikyow, T.; Heske, C.; Buecheler, S.; Tiwari, A. N.; Bär, M. Formation of a K-In-Se Surface Species by NaF/KF Postdeposition Treatment of $\mathrm{Cu}(\mathrm{In}, \mathrm{Ga}) \mathrm{Se}_{2}$ Thin-Film Solar Cell Absorbers. ACS Appl. Mater. Interfaces 2017, 9, 3581-3589.

(60) Friedlmeier, T. M.; Jackson, P.; Kreikemeyer-Lorenzo, D.; Hauschild, D.; Kiowski, O.; Hariskos, D.; Weinhardt, L.; Heske, C.; Powalla, M. A Closer Look at Initial CdS Growth on High-Efficiency $\mathrm{Cu}(\mathrm{In}, \mathrm{Ga}) \mathrm{Se}_{2}$ Absorbers Using Surface-Sensitive Methods. 2016 IEEE 43rd Photovoltaic Specialists Conference (PVSC), 2016; pp 457-461.

(61) Raghuwanshi, M.; Wuerz, R.; Cojocaru-Mirédin, O. Interconnection between Trait, Structure, and Composition of Grain Boundaries in $\mathrm{Cu}(\mathrm{In}, \mathrm{Ga}) \mathrm{Se}_{2}$ Thin-Film Solar Cells. Adv. Funct. Mater. 2020, 30, 2001046.

(62) Schöppe, P.; Schönherr, S.; Jackson, P.; Wuerz, R.; Wisniewski, W.; Ritzer, M.; Zapf, M.; Johannes, A.; Schnohr, C. S.; Ronning, C. 
Overall Distribution of Rubidium in Highly Efficient $\mathrm{Cu}(\mathrm{In}, \mathrm{Ga}) \mathrm{Se}_{2}$ Solar Cells. ACS Appl. Mater. Interfaces 2018, 10, 40592-40598.

(63) Rau, U.; Taretto, K.; Siebentritt, S. Grain Boundaries in $\mathrm{Cu}(\mathrm{In}, \mathrm{Ga})(\mathrm{Se}, \mathrm{S})_{2}$ Thin-Film Solar Cells. Appl. Phys. A: Mater. Sci. Process. 2009, 96, 221-234.

(64) Persson, C.; Zunger, A. Anomalous Grain Boundary Physics in Polycrystalline CuInSe $e_{2}$ : The Existence of a Hole Barrier. Phys. Rev. Lett. 2003, 91, 266401.

(65) Hellman, O. C.; Seidman, D. N. Measurement of the Gibbsian Interfacial Excess of Solute at an Interface of Arbitrary Geometry Using Three-Dimensional Atom Probe Microscopy. Mater. Sci. Eng., A 2002, 327, 24-28.

(66) Grini, S.; Sopiha, K. V.; Ross, N.; Liu, X.; Bjørheim, T. S.; Platzer-Björkman, C.; Persson, C.; Vines, L. Strong Interplay between Sodium and Oxygen in Kesterite Absorbers: Complex Formation, Incorporation, and Tailoring Depth Distributions. Adv. Energy Mater. 2019, 9, 1900740.

(67) Grini, S.; Aboulfadl, H.; Ross, N.; Persson, C.; PlatzerBjörkman, C.; Thuvander, M.; Vines, L. Dynamic Impurity Redistributions in Kesterite Absorbers. Phys. Status Solidi B 2020, 257, 2000062.

(68) Chirilă, A.; Reinhard, P.; Pianezzi, F.; Bloesch, P.; Uhl, A. R.; Fella, C.; Kranz, L.; Keller, D.; Gretener, C.; Hagendorfer, H.; Jaeger, D.; Erni, R.; Nishiwaki, S.; Buecheler, S.; Tiwari, A. N. PotassiumInduced Surface Modification of $\mathrm{Cu}(\mathrm{In}, \mathrm{Ga}) \mathrm{Se}_{2}$ Thin Films for HighEfficiency Solar Cells. Nat. Mater. 2013, 12, 1107-1111.

(69) Jackson, P.; Wuerz, R.; Hariskos, D.; Lotter, E.; Witte, W.; Powalla, M. Effects of Heavy Alkali Elements in $\mathrm{Cu}(\mathrm{In}, \mathrm{Ga}) \mathrm{Se}_{2}$ Solar Cells with Efficiencies up to 22.6\%. Phys. Status Solidi RRL 2016, 10, $583-586$.

(70) Erslev, P. T.; Lee, J.; Hanket, G. M.; Shafarman, W. N.; Cohen, J. D. The Electronic Structure of $\mathrm{Cu}\left(\mathrm{In}_{1-\mathrm{x}} \mathrm{Ga}_{\mathrm{x}}\right) \mathrm{Se}_{2}$ Alloyed with Silver. Thin Solid Films 2011, 519, 7296-7299.

(71) Prosa, T. J.; Strennen, S.; Olson, D.; Lawrence, D.; Larson, D. J. A Study of Parameters Affecting Atom Probe Tomography Specimen Survivability. Microsc. Microanal. 2019, 25, 425-437.

(72) Persson, C.; Zhao, Y. J.; Lany, S.; Zunger, A. N-Type Doping of $\mathrm{CuInSe}_{2}$ and $\mathrm{CuGaSe}_{2}$. Phys. Rev. B: Condens. Matter Mater. Phys. 2005, 72, 035211.

(73) Sopiha, K. V.; Larsen, J. K.; Donzel-Gargand, O.; Khavari, F.; Keller, J.; Edoff, M.; Platzer-Björkman, C.; Persson, C.; Scragg, J. J. S. Thermodynamic Stability, Phase Separation and Ag Grading in $(\mathrm{Ag}, \mathrm{Cu})(\mathrm{In}, \mathrm{Ga}) \mathrm{Se}_{2}$ Solar Absorbers. J. Mater. Chem. A 2020, 8, $8740-8751$.

(74) Hariskos, D.; Powalla, M. Thermodynamic Limitations for Alkali Metals in $\mathrm{Cu}(\mathrm{In}, \mathrm{Ga}) \mathrm{Se}_{2}$. J. Mater. Res. 2017, 32, 3789-3800.

(75) Chen, J.; Shen, H.; Zhai, Z.; Liu, F.; Zhu, Z.; Luo, M. Performance and Stability Enhancement of $\mathrm{Cu}(\mathrm{InGa}) \mathrm{Se}_{2}$ Solar Cells on Ultrathin Glass by Potassium Incorporation. Mater. Lett. 2020, 271, 127749.

(76) Taguchi, N.; Tanaka, S.; Ishizuka, S. Direct Insights into $\mathrm{RbInSe}_{2}$ Formation at $\mathrm{Cu}(\mathrm{In}, \mathrm{Ga}) \mathrm{Se}_{2}$ Thin Film Surface with $\mathrm{RbF}$ Postdeposition Treatment. Appl. Phys. Lett. 2018, 113, 113903.

(77) Lin, T.-Y.; Khatri, I.; Matsuura, J.; Shudo, K.; Huang, W.-C.; Sugiyama, M.; Lai, C.-H.; Nakada, T. Alkali-Induced Grain Boundary Reconstruction on $\mathrm{Cu}(\mathrm{In}, \mathrm{Ga}) \mathrm{Se}_{2}$ Thin Film Solar Cells Using Cesium Fluoride Post Deposition Treatment. Nano Energy 2020, 68, 104299.

(78) Muzzillo, C. P.; Mansfield, L. M.; Ramanathan, K.; Anderson, T. J. Properties of $\mathrm{Cu}_{1-\mathrm{x}} \mathrm{K}_{\mathrm{x}} \mathrm{InSe}_{2}$ Alloys. J. Mater. Sci. 2016, 51, 68126823.

(79) Shannon, R. D. Revised Effective Ionic Radii and Systematic Studies of Interatomic Distances in Halides and Chalcogenides. Acta Crystallogr., Sect. A: Cryst. Phys., Diffr., Theor. Gen. Crystallogr. 1976, 32, 751-767.

(80) Kühn, G.; Möller, W.; Engel, W. Heats and Entropies of Fusion of ABC2 Chalcopyrite Semiconductors. Thermochim. Acta 1984, 78, 129-134. 